\title{
One Size Does Not Fit All: Toward an Evidence-Based Framework for Determining Online Course Enrollment Sizes in Higher Education
}

\author{
Susan H. Taft \\ Kent State University (Retired) \\ Karen Kesten and Majeda M. El-Banna \\ The George Washington University
}

\begin{abstract}
Class enrollment sizes for online learning in higher education, a topic of persistent interest in the academic literature, impact student learning, pedagogical strategies, school finances, and faculty workload. Yet in the research literature, class size is addressed with insufficient specificity to provide enrollment direction. Seeking guidelines for determining online class sizes, the authors conducted a qualitative research synthesis from 43 recent higher education journals, yielding 58 evidence-based articles. It is clear that no one size fits all. Findings reflect that large classes $(\geq 40$ students) are effective for foundational and factual knowledge acquisition requiring less individualized faculty-student interaction. Small classes ( $\leq 15$ students) are indicated for courses intending to develop higher order thinking, mastery of complex knowledge, and student skill development. Pedagogical intent should dictate class size. Using well-established learning theories, the authors describe current understandings of online enrollments and propose an analytical framework for pedagogically driven, numerically specific class sizes.
\end{abstract}

Highlights:

- There is academic interest in online course sizes in higher education.

- Research indicates "no one size fits all" online classes.

- Class sizes should be based on learning level and identified pedagogical intent.

- Large classes are appropriate for foundation-level learning.

- Small classes are appropriate for learning requiring higher order thinking.

Keywords: class size, online pedagogy, objectivism, constructivism, Bloom's taxonomy, community of inquiry

Taft, S.H., Kesten, K., \& El-Banna, M.M. (2019). One size does not fit all: Toward an evidencebased framework for determining online course enrollment sizes in higher education.

Online Learning, 23(3), 188-233. doi:10.24059/olj.v23i3.1534 
One Size Does Not Fit All: Toward an Evidence-Based Framework

for Determining Online Course Enrollment Sizes in Higher Education

\section{One Size Does Not Fit All: Toward an Evidence-Based Framework for Determining Online Course Enrollment Sizes in Higher Education}

A few years ago, I [was] trying to come to grips with the implications of Massive Open Online Courses (or MOOCs). They were supposed to be the innovation that would not only make most college professors obsolete, but force countless colleges to close as every student would prefer to hear Harvard's best lecture rather than get their course content from the community-college professor in their neighborhood. Of course, any college professor who cares one whit about teaching understands that education involves a lot more than just conveying information.... If we automated learning, information would still travel from the brain of the professor to the brain of the student, but we'd never know exactly how well students understood it. You might as well just hit 'play' on a tape of someone else's lecture, then leave the room to do something else. (Rees, 2017, paras. 7-10)

In the past 15 years, many higher education institutions have been transformed by the adoption and implementation of distance learning programs. Choices for students now range among going to a traditional college and taking all courses face-to-face, taking some courses faceto-face and others online, not stepping onto a college campus and taking courses online, and acquiring an entire degree online. Online learning in universities has come of age and, with its developing maturity, has triggered a need to understand factors influencing how effectively students learn via distance education. Policies on online learning and class sizes are among those that college faculty view as overdue for examination (Richardson, Koehler, Besser, Caskurlu, Lim, \& Mueller, 2015).

Class size is a recurring and perennial issue in the economics of education. It invokes an evaluation of education production versus education costs, consequential implications for resource generation and allocation (Russell \& Curtis, 2013). The effects of class size on the degree and quality of learning have been debated and studied for decades at the K-12 level of formal education (e.g., Blatchford, Bassett, \& Brown, 2011; Sapelli \& Illanes, 2016), and, more recently, in higher education (Chapman \& Ludlow, 2010; Richardson et al., 2015; Tynan, Ryan, \& Lamont-Mills, 2015; Watson, Handel, \& Maher, 2016). To this day, however, there has been no conclusive evidence by which university administrators determine enrollment sizes for online courses (Udermann, 2015). This article presents the accumulated research evidence on online education class size, examines relevant theories of pedagogical intent and methods for college courses, presents an analytical framework for enrollment decisions, and proposes specific numbers to stabilize class-size categories from small to large.

\section{Background}

New learning technologies developed in the early 21 st century prompted universities to develop distance learning strategies. Many university administrators pursued market expansion through the development of online courses, and with them an increase in student enrollment for purposes of revenue generation and/or cost reduction (Benton \& Pallett, 2013; Chapman \& Ludlow, 2010; Chen, deNoyelles, Zydney, \& Patton, 2017; Colwell \& Jenks, 2004; Diette \& Raghav, 2015; Jones, 2015; Maringe \& Sing, 2014; Mupinga \& Maughan, 2008; Pelech et al., 2013; Russell \& Curtis, 2013). In the rapidly changing technology-driven conditions within universities, an upward creep of online class sizes emerged and began to raise faculty concerns that educational effectiveness could be threatened (Jones, 2015; Ravenna, 2012; Seethamraju, 
2014; Smith, Brashen, Minor, \& Anthony, 2015; Snowball, 2014). Indeed, throughout this period of online growth there appears to have been little systematic application of learning theory principles to decisions on a cluster of issues arising for online courses: class sizes, effective pedagogical methods, rising university costs and revenues, faculty workload, and accommodating diverse student learning needs (Tynan et al., 2015; Mupinga \& Maughan, 2008).

There is an acknowledged lack of consensus on how class size affects learning in online university courses (Gleason, 2012; Haynie, 2014; Maringe \& Sing, 2014; Udermann, 2015). In class size research, the lack of consensus likely results from there being too many relevant variables to capture, measure, and control consistently across settings (e.g., Arias \& Walker, 2004; Arzt, 2011; Kingma \& Keefe, 2006; Lai, 2015; Lindley, Ashwill, Cipher, \& Mancini, 2017; Mandel \& Sussmuth, 2011; Maringe \& Sing, 2014; Monks \& Schmidt, 2011; Morrison, 2015; Palmer \& Smith, 2013; Richardson et al., 2015; Walls, 2016). Alternatively, perhaps findings on class sizes could lead to implications that would be perceived as a threat to university finances, or pique political sensitivities regarding varying populations' access to equal educational opportunity (Colwell \& Jenks, 2004; Curriculum Committee, 2011-2012; Diette \& Raghav, 2015; Maringe \& Sing, 2014; Russell \& Curtis, 2013). Whatever the reasons, no existing convergence of research evidence provides guidance for determining optimal online class sizes at different educational levels and under varying contextual conditions - that is, no one size fits all (Beattie \& Thiele, 2016; Bettinger, Doss, Loeb, Rogers, \& Taylor, 2017; Bristol \& Kyarsgaard, 2012; Chapman \& Ludlow, 2010; Cheng, 2011; Colwell \& Jenks, 2004; Curriculum Committee, 2012; Freeman, 2015; Haynie, 2014; Hewitt \& Brett, 2007; Horning, 2007; Johnson, 2010; Kim, 2013; Lee, Dapremont, \& Sasser, 2011; Liu, 2012; Mandernach \& Holbeck, 2016; Morrison, 2015; Mupinga \& Maughan, 2008; Parks-Stamm, Zafonte, \& Palenque, 2016; Qiu, Hewitt, \& Brett, 2012; Ravenna, 2012; Roby, Ashe, Singh, \& Clark, 2013; Russell \& Curtis, 2013; Seaton \& Schwier, 2014; Shaw, 2013; Sorensen, 2014, 2015; Taft, Perkowski, \& Martin, 2011; Tynan et al., 2015; Walls, 2016; Watson et al., 2016).

An extensive research base supports the efficacy of both in-person and online instruction across university academic disciplines and for many, if not all, types of learning (e.g., BenbunanFich, Hiltz, \& Harasim, 2005; Means, Toyama, Murphy, Bakia, \& Jones, 2010; Xu \& Jaggars, 2014). The equivalence of learning online versus face-to-face in the cognitive domain is wellsupported by research. Learning efficacy is less established for skills learning, role modeling, or student socialization into a discipline, and for lower performing students (Artemiou, Adams, Vallevand, Violato, \& Hecker, 2013; Benton \& Pallett, 2013; Bettinger \& Loeb, 2017; Jones, 2015).

In a relatively short period, methods of effective online instruction/course delivery and student learning have been explored and documented by educational researchers, but no consistent results exist on practices associated with class size decisions. By eliminating the constraints of brick-and-mortar spaces, the rise of distance learning has revealed that college courses have no inherent or clear class size parameters (Pelech et al., 2013; Sorensen, 2014), nor have universities developed a framework for examining relevant parameters and making educationally informed decisions on online class size.

We define class size in universities as the number of students assigned to a single teacher in any given college or postgraduate course. Determining whether a course has one teacher or more is complicated by the presence of a professor and support staff, such as teaching assistants or facilitators. Some degree of skilled support may be efficient for a professor handling a large lecture 
course, but there will be elements of the teaching task-designing the course, possessing deep subject matter knowledge, addressing complex issues, grading advanced work, giving expert feedback - that require the professor's singular knowledge and experience. To keep the calculations in this article simple, we adhere to the definition of class size as number of students assigned to a single instructor. Yet in enrollment decisions, each institution and each researcher that hopes to think clearly about class size needs to seek a consistent way to address the nexus of student numbers, staffing, and pedagogical methods.

Traditionally, universities have followed an implicit set of assumptions about the "right" class size. Lower division undergraduate courses have tended to be lecture based and large, often intended for the transmission of factual and foundational information to students (Maringe \& Sing, 2014). As students progress into upper division courses in their major and minor fields of study, class sizes have tended to fall; by senior year, medium-sized and smaller seminar-sized courses become more common. Graduate programs follow a parallel trend, with early courses tending toward a medium size and later courses reducing enrollments to smaller seminars (Holzweiss, Joyner, Fuller, Henderson, \& Young, 2014). Doctoral courses are typically taught in small seminars. While the reasoning behind these course size patterns is rarely made explicit, educational theories suggest that varying class size based on level of student educational development is an inherently sound approach (Taft et al., 2011).

As demonstrated in these established college course enrollment practices, undergraduate and graduate courses are implicitly assigned different sizes across the 4-year undergraduate and the 2- to 5-year graduate learning cycles. Different sizes have persisted across learning levels, are normative, and reflect longevity. That is, undergraduate and graduate courses decline in size as learning level rises, while learning that moves beyond factual knowledge to the development of students' abilities to exercise critical thinking and judgment, often in the face of complexity, calls for smaller student-faculty ratios (Walls, 2016).

With the growth of online learning, new demands have caused the faculty role to expand. While maintaining mastery of the subject matter and pedagogy, faculty now are challenged to learn and apply ever-changing course technologies, maintain currency in emerging learning media, assume new teaching role tasks, and adapt course structures to online learning environments using current instructional designs (Jones, 2015). Additionally, across disciplines many faculty do not have a sound understanding of current learning theories that guide optimal student learning online. In their pedagogical choices, faculty tend to rely on personal experience - how they have been taught, trial and error, and intuition - rather than evidence-based pedagogical research. There is rising consensus that becoming an effective online teacher requires the integration of knowledge of subject matter content, learning theory pedagogy, and digital technologies. To these ends, faculty must become lifelong learners in areas outside their disciplinary expertise (Mbati \& Minnaar, 2015; Tynan et al., 2015).

A sizeable research literature exists on methods of effective online education. Multiple factors are reported to mediate the relationship between acts of teaching and actual student learning, including course level and subject matter complexity; the extent and nature of student diversity in courses; number of course-specific intensive grading assignments necessitating faculty feedback; faculty experience teaching online; adequacy of university information technology support services; user-friendliness and technical stability of the online platform; faculty workload policy; and course enrollment sizes. While research results are somewhat mixed, teaching online has generally been acknowledged to be more time-consuming and labor-intensive than face-to- 
face teaching (Freeman, 2015; Jones, 2015; Maringe \& Sing, 2014; Mupinga \& Maughan, 2008; Sorensen, 2014, 2015; Sword, 2012; Taft et al., 2011; Tomei, 2006; Tynan et al., 2015). Greater labor intensity in teaching online combined with expanded role responsibilities heighten faculty frustrations associated with large class sizes.

Additional support for the relevance of class size comes from the U.S. News and World Report college rankings scoring system that, under the category of faculty resources, ranks colleges' quality by awarding credit for undergraduate classes with fewer than 20 students. It assigns minimal to no scoring credit for classes with 40 or more students (Morse, Brooks, \& Mason, 2018; Udermann, 2015).

As faculty members from two different colleges of nursing, the authors have ridden the wave of distance learning inception and growth at their universities, and in the process have observed the need to bring sound learning theory principles to bear on course enrollment decisions (cf. Benton \& Pallett, 2013; Salley \& Shaw, 2015). We have experienced the push and pull of revenue pressures conflicting with faculty-perceived goals of quality student learning. University administrators can - and in some settings do - raise enrollment numbers in courses without examining the impact on students' attainment of learning objectives (Maringe \& Sing, 2014; Mupinga \& Maughan, 2008; Qiu et al., 2012; Russell \& Curtis, 2013; Snowball, 2014; Tynan et al., 2015). In talking with peers from across the United States, the authors heard the echo of a question that education researchers have asked for decades: What is the right balance between an institution's financial goals in online education courses (i.e., raising enrollment levels) and the quality of the education experience for online students (Colwell \& Jenks, 2004)? What are enrollment best practices? How do we objectively determine whether classes are too big or too small? Policy decisions about appropriate class sizes have engaged the authors personally, and been recognized by faculty in other college settings, as a potentially charged issue between university administration and faculty. Our research found that university practices justifying online course sizes are virtually unsupported by educational theory or evidence.

According to the Curriculum Committee of the Academic Senate for California Community Colleges (2012), course enrollment sizes are important academic concerns. The Committee concluded that

appropriate course enrollment maximums are an essential aspect of guaranteeing the quality of instructional programs. Colleges must consider many factors in establishing these enrollment limits, including ... instructor workload, and the fiscal viability of the institution. However, the primary basis of any determination regarding enrollment maximums should be the pedagogical factors that influence the success of the students in the course [emphases added]. ...

In the end, the goal is to find the right balance between maximizing learning opportunities for students and assuring program and college viability. While these two perspectives are not always in conflict, when they do conflict, finding the right ratio should be based first on the pedagogical factors that facilitate student success. (pp. 1, 3)

Indeed, attaining both educational effectiveness and fiscal responsibility in universities are goals to be honored. The authors of this article fully respect the need for schools to generate revenues in excess of their expenditures. We recognize that there are justifiable reasons for courses that can accommodate large enrollments even while others require small ones. 
One Size Does Not Fit All: Toward an Evidence-Based Framework

for Determining Online Course Enrollment Sizes in Higher Education

\section{Literature Review}

Given the financial and educational impacts of class sizes on universities, this study explored recently published research from 43 online education journals for guidance on establishing online class sizes. We identified 58 articles relevant to the topic. (Please note that the Methods section describes journal and article selection procedures.)

The 58 reviewed studies on class size displayed considerable variation in research purpose, contexts, and theory. Study foci, for example, spanned variables such as the relationship between class size and student achievement; student perceptions of the learning experience; student communication and participation behaviors; skill development; differentials in student learning levels; and how diverse student bodies were affected by class size. Others considered size relative to course design features and differences among selected learning technologies. Additionally, some articles focused on the time expenditures of faculty workloads, pedagogical choices, and students' evaluation of instruction in small versus large courses. Across studies, little attention was paid to class size differentiation between undergraduate and graduate courses. While the selected articles commonly used terminology such as "small," "medium," and "large" to describe class sizes, only 18 provided specific recommendations for numbers of students, and even these were not consistent with each other. For readers interested in details of the reviewed studies, annotated summaries are displayed in Table 1.

Table 1.

Summary of Reviewed Articles Addressing class Size ( $\left.n=58^{*}\right)$

Author(s), Date, Title, and Journal Artemiou, E., Adams, C.L., Vallevand, A., Violato, C., \& Hecker, K. G. (2013). Measuring the effectiveness of small-group and web-based training methods in teaching clinical communication: A case comparison study. Journal of Veterinary Medical Education, 40(3).

Batts, D. (2008, December). Comparison of student and instructor perceptions of best practices in online technology courses. Merlot Journal of Online Teaching and Learning, 4(4).

Beattie, I. R. \& Thiele, M. (2016). Connecting in class? College class size and inequality in academic social capital. The Journal of Higher Education, 87(3).

\section{Focus}

Study's objectives were to (1) assess the effectiveness of small-group face-to-face and web-based methods for teaching communication skills, and (2) identify which training method is more effective in helping students to develop communication skills.

\section{Recommendations \\ [Related Educational Theory]}

Study results showed that (1) small-group training was the most effective teaching approach in enhancing communication skills and resulted in students scoring significantly higher on the postintervention measure of skills. "Small-group" size not identified.

[Objectivism-constructivism, $\mathrm{CoI}$ ]
Applied to online environments, study investigated the perception of students and instructors re: the use of Chickering \& Gamson's (1987) "Seven Principles for Good Practice in Undergraduate Education."

Principles with high scores in the courses included student-faculty contact and prompt feedback; low scores on 4 of the 7 principles: active learning, cooperation among students, time on task, and diverse talents and ways of learning.

At a public research university, researchers studied college students' interactions with professors and peers about academic matters. Such interactions create social capital and result in better student outcomes. Larger classes were found to hinder a key type of beneficial student engagement: student-initiated discussions with professors and peers across campus about academic and career matters. Classes were all face-to-face.
Only 3 of the 7 principles had perceived course means of medium to high. Administrators should consider institutionalizing the principles by training, assessment, and course design. An area where administrators can assist faculty is to keep online class size low enough to create a sense of community. "Low enough" not designated. [Objectivismconstructivism, $\mathrm{CoI}]$

Compared to students enrolled in smaller classes, those in larger classes had significantly fewer interactions with professors about course material and with peers about course-related ideas. Class size negatively influenced first-generation students' likelihood of talking to professors or TAs about ideas from class. For Black and Latino students, larger classes also had profound negative effects on initiating discussions of future careers. [CoI]

\footnotetext{
*Unless noted in first column, all articles are from peer-reviewed journals.
} 
One Size Does Not Fit All: Toward an Evidence-Based Framework

for Determining Online Course Enrollment Sizes in Higher Education

\section{Author(s), Date, Title, and Journal}

Bedard, K., \& Kuhn, P. (2008).

Where class size really matters:

Class size and student ratings of instructor effectiveness.

Economics of Education Review, 27(3).

Benton, S. L., \& Pallett, W. H.

(2013). Class size matters. Inside Higher Education. Retrieved

from https://www.

insidehighered.com/views/2013/0

1/29/essay-importance-class-size-

higher-education

Not research-based or peer-

reviewed.

Bettinger, E., Doss, C., Loeb, S., Rogers, E., \& Taylor, E. (2017).

The effects of class size in online college courses: Experimental evidence. Economics of

Education Review, 58.

Bettinger, E., \& Loeb, S. (2017). Promises and pitfalls of online education (Forthcoming publication in a peer-reviewed journal). Brookings. Retrieved from

https://www.brookings.edu/ research/promises-and-pitfallsof-online-education/

Betts, K. (2008). Online Human

Touch (OHT) instruction and programming: A conceptual framework to increase student engagement and retention in online education, Part 1. MERLOT Journal of Online Learning and Teaching, 4(3).

Bristol, T. J., \& Kyarsgaard, V. (2012). Asynchronous discussion: A comparison of larger and smaller discussion group size. Nursing Education Perspectives, 33(6).

\section{Focus}

Examined the impact of class size on student evaluations of instructor performance using data on all size on student evaluations of instructor effectiveness. economics classes offered over 7 years at a large western university; controlled for both instructor and course fixed effects.

Correlates of smaller class sizes are more creativity and communication skills; more challenge; higher levels of thinking on Bloom's taxonomy; more inspiration from instructor, more motivation, enthusiasm; more effort by students and better study/work habits; higher student satisfaction and ratings of instructor; positive attitudes about the discipline; and greater student average progress on course objectives.

Study used a large sample; examined class size effects on student success in the course and on student persistence in college. Found little evidence of class size effects for a range of course types. Study could only estimate the short-term - not the long-termeffects of increasing class size.

Study comparing students in online vs. face-to-face courses used data from DeVry University, a large forprofit college with an undergraduate enrollment of more than 100,000 students. Courses were offered largely identically, online, and in-person. Included data from over 230,000 students enrolled in 168,000 sections of more than 750 different courses.

Equivalence of student population characteristics online vs. face-to-face not clarified in methodology. Implemented an interactive and personalized approach to online education at one university program, resulting in high student retention rates and high levels of student satisfaction.

Studied differences in student outcomes for class sizes of 12 vs. 23. Mixed results.
Categorized class size as small (10-14), medium (15$34)$, large (35-49), and very large (50+). Instructors vary course objectives based on class size: In very large classes they are more likely to emphasize learning factual knowledge, low on Bloom's taxonomy, and less likely to stress research projects, developing oral \& written communication skills, and creativity than are those in small \& medium classes. [Objectivism-constructivism, Bloom's taxonomy, $\mathrm{CoI}]$

For online classes with an average of 30 students, increasing the class size $10 \%$ did not significantly affect student grades, enrollment in the next term, or credits attempted the next term. Tested only small changes in class sizes, and thus results unlikely to be applicable to large changes in class size, such as increasing numbers $\geq 25 \%$.

Found that students in online courses performed substantially worse than students in traditional courses; experience in the online courses impacted students' future class performance while increasing the likelihood of dropping out of college. The negative effects of taking online courses were concentrated in the lowest-performing students. Concluded that online courses yielded worse average outcomes than in-person courses. typically did not have more than $20-25$ students in an online course, and less than 20 students in specialization courses.

No statistically significant difference in student outcomes for group size or strategy. But the data suggested that smaller group size would help students "dig deeper" into the content being explored. Recommends studies on class size and students' critical thinking abilities. [Objectivismconstructivism, Bloom's taxonomy]
The graduate level academic program in this study 
One Size Does Not Fit All: Toward an Evidence-Based Framework

for Determining Online Course Enrollment Sizes in Higher Education

\section{Author(s), Date, Title, and Journal}

Chapman, L., \& Ludlow, L. (2010). Can downsizing college class sizes augment student outcomes? An investigation of the effects of class size on student learning. The Journal of General Education, 59(2).

Cheng, D. A. (2011). Effects of class size on alternative educational outcomes across disciplines. Economics of Education Review, 30(5).

Colwell, J., \& Jenks, C. (2004). The upper limit: The issues for faculty in setting class size in online courses. Teaching Online in Higher Education 2004 (TOHE) Conference Proceedings. Retrieved from: https://www.utm.edus/department s/ncate/ documents/015 theupperlimit.pdf

\section{Focus}

After student effort and instructor quality were controlled, study used student course evaluations to examine the relationship between class size and perceived student learning. Data provided through student ratings of instruction from a single university instructor's courses of a total of 109 classes, taught for over 20 years. In classes ranging from 3-52 students, 2,360 students filled out the evaluations. The courses ranged from undergraduate to doctorallevel seminars. Many instructors were aware that course and instructor ratings have been found to be negatively related to their class sizes.

Class size influences how instructors design their pedagogies.

Study used self-reported ratings of student learning and instructor and course recommendations as the outcome measure to estimate class size effects across 24 disciplines. Different disciplines had highly variable class sizes, some into the hundreds. The data spanned 24 departments, 2,110 courses, 1,914 instructors, and 10,357 observations from fall 2004 to spring 2009.

This presentation asks the question, What is the right balance between the economic issues of online instruction and the quality of the education experience for the asynchronous online student? Faculty can face pressures from administrators to maximize class sizes in online courses to make them more efficient or profitable. It is the authors' opinion that this is an opportunity for profit only at the expense of educational quality or professors. There is consensus that higher order thinking in online courses requires both much more development and interaction time than do traditional courses. Some researchers agree that distance education is not cost-efficient.

\section{Recommendations [Related Educational Theory]}

For each additional 10 students in an undergraduate or graduate class, this study found a $4 \%$ statistically significant negative relationship between class size and perceived student learning, and between class size and students' ratings of the instructor. Student engagement was positively associated with students' perceived learning. Neither student nor instructor variables individually or collectively offset the negative effects of larger classes. While increasing class sizes during times of increased education costs presents a relatively seductive way to save money, it introduces a burden to learning that is difficult for students and instructors to overcome, despite their best efforts.

Overall, this study found that greater class size had negative and significant effects on student satisfaction in 4 disciplines, statistically insignificant effects on outcomes in 10 disciplines, and inconclusive or mixed effects in 10 disciplines. Author's view is that no discipline benefits from increasing course enrollments.

Class size is inconsistent from department to department within a university, as well as between higher education institutions. Anecdotally, class size for online courses varies. From survey data, size varies from 1-100 to many hundreds of students. Often, there is no standard on class size limits for online courses within an institution. Too few students in a course often yield difficulty generating meaningful discussions; too many create an excessive number of messages, causing frustration for group members who cannot keep up. Group size must be sufficiently large to encourage activity but not so large that the sense of group connectedness is lost. This presumes that communication is occurring between the instructor and the students and among the students themselves. Authors recommend a maximum course size of 20 students for undergraduate courses and 8-15 for graduate courses. [Bloom's taxonomy] 
One Size Does Not Fit All: Toward an Evidence-Based Framework

for Determining Online Course Enrollment Sizes in Higher Education

\section{Author(s), Date, Title,} and Journal

Curriculum Committee, The Academic Senate for California Community Colleges. (2012).

Setting course enrollment maximums: Process, roles, and principles. Retrieved from http://www.asccc.org/sites/defaul t/files/

ClassCapsS12_0.pdf

Not a peer-reviewed source

De Giorgi, G., Pellizzari, M., \& Woolston, W.G. (2012). Class size and class heterogeneity. Journal of the European Economic Association, 10(4).

Diette, T. M., \& Raghav, M. (2015). Class size matters: Heterogeneous effects of larger classes on college student learning. Eastern Economic Journal, 41(2).

El Tantawi, M. M. A., Abdelsalem, M. M., Mourady, A. M., \& Elrifae, I. M. B. (2015). eAssessment in a limitedresources dental school using an open-source learning management system. Journal of Dental

Education, 79(5).

Freeman, L. A. (2015). Instructor time requirements to develop and teach online courses. Online Journal of Distance Learning Administration, 18(1).

\section{Focus}

Appropriate course enrollment maximums are an essential aspect of guaranteeing the quality of instructional programs. Colleges must consider many factors in establishing these enrollment limits, but the primary basis of any determination regarding enrollment maximums should be the pedagogical factors that influence the success of the students in the course, including the following:

- faculty time spent assessing/evaluating student work,

- volume of written work,

- volume of discussions, and

- course outcomes demanding more higher order, complex thinking skills from students.

Class size determinations should be shared with the bargaining unit and included in the faculty union contract.

Courses addressed were face-to-face.

Study of a single university's 1,100 undergraduate students in management, finance, and economics. Classes large: 64-172, with an overall mean of 135 and a standard deviation of 28 . Courses were face-toface.

Study examined the relationship between class size and student achievement at a selective liberal arts college. Classes had a mean of 20.2 and a standard deviation of 11 students. Findings suggested that attempts to control costs harm students, particularly those least likely to graduate.

The aim of this study was to evaluate the use of an eassessment tool on students that was provided through an open-source learning management system at a limited-resources dental school. Studied students' perceptions of the e-assessment, a single and summative evaluation of learning. Classes large, with 285 students registered in two courses.

Study of time demands for faculty in online vs. faceto-face courses. Indicates content development, presemester setup, and instructor-student interaction during courses clearly more time-consuming online. Assessing/grading are also, but less so. Some factors diminish with repeat course teaching. The time demands of online teaching are more associated with pedagogy than with technology.

\section{Recommendations \\ [Related Educational Theory]}

The number of students in the class should be appropriate to the method of teaching used in the class (e.g., lecture, lab, discussion); conducive to the use of a variety of effective grading processes (e.g., writing assignments, discussions, exams); aligned with course outcomes demanding more higher order, complex thinking skills from students; and expected faculty time spent assessing/evaluating student work. Students should receive timely and constructive feedback (formative and summative) on assignments in as many ways as possible. The National Council of Teachers of English (NCTE) recommends a class size of 20 for college English courses and 15 for basic skills courses. The American Mathematics Association of Two Year Colleges recommends a ratio of 30 students for one teacher. [Objectivismconstructivism, Bloom's taxonomy, $\mathrm{CoI}]$

Study found that class size had a small but substantial impact on student academic performance. A reduction in class size by 20 students increased the average grade by 0.1 standard deviations; the effect of class size on student performance was larger for men and for lower income students.

Study found that grades of students decrease as class size increases. Relatively vulnerable students, such as first years or those with low SAT scores, experienced, on average, larger negative effects from increases in class sizes.

Using e-assessments with large numbers of students was efficient for testing students' learning of factual information. Study concluded that e-assessment can be used at minimal cost in schools with limited resources and large class sizes - and with low demands on faculty and teaching staff time. Study supports the use of computer-graded student testing on factual learning; accommodates large numbers of students with limited workload effort by faculty. [Bloom's taxonomy, objectivism-constructivism, $\mathrm{CoI}]$

Due to teaching intensity, study survey found smaller university enrollments in online than traditional courses. Class size tended to be demarcated at around 30 or fewer students for online courses. Of surveyed faculty, $81 \%$ indicated it was more time-consuming to develop and teach an online than a face-to-face course. Author calls for research on impact of course enrollments. 
One Size Does Not Fit All: Toward an Evidence-Based Framework

for Determining Online Course Enrollment Sizes in Higher Education

\section{Author(s), Date, Title,} and Journal

Gleason, J. (2012). Using technology-assisted instruction and assessment to reduce the effect of class size on student outcomes in undergraduate mathematics courses. College Teaching, 60(3).

Goldman, Z. (2012). Online MBA asynchronous discussion workload and value perceptions for instructors and learners: Working toward an integrated educational model for professional adults. Journal of Online Learning and Teaching, $8(3)$ Haynie, D. (2014, September 26). Experts say class size can matter for online students. U.S. News \& World Report, Higher Education. Not a peer-reviewed source.

Hewitt, J., \& Brett, C. (2007). The relationship between class size and online activity patterns in asynchronous computer conferencing environments. Computers \& Education, 49(4).

Holzweiss, P. C., Joyner, S. A., Fuller, M. B., Henderson, S., \& Young, R. (2014). Online graduate students' perceptions of best learning. Distance Education, 35(3).

\section{Focus}

Study analyzed student outcomes generated in college algebra and applied calculus courses with class sizes ranging from 37 to 129; courses had common syllabi, homework, quizzes, and tests. Found medium classes (30-55 students) had little to no benefit over large classes (110-130 students) in student learning and achievement, with large classes having small-medium positive-effect sizes over medium classes in the area of student satisfaction.

Study reviews the outcomes of a yearlong survey examining the perceived workload and value of asynchronous discussions by MBA adult learners and instructors. Courses used a discussion guideline.

The research behind class size in an online environment is inconclusive.

For asynchronous classes, where students rely mainly on readings, prerecorded lectures, and discussion boards, experts are divided on whether to pay attention to the number of classmates in a course.

Research question: What is the relationship between class size and student reading and note writing in online courses? Earlier studies on class size concluded that the ideal enrollment appears to be between 8 and 30 students, depending on the type of course. Class size affects social presence, more easily established in small than large classes. Large classes create information overload.

Studied reports of online master's students regarding their best learning experiences. Differences are inherent between how graduate and undergraduate students learn. Expectations indicate that undergraduates learn foundational content in a general curriculum and within a broad academic field of study, while graduate students are focused on advanced content and skill development for a specific professional field. Graduate-level learning demands an increased level of critical thinking, and understanding and appreciating the flexible nature of knowledge.

\section{Recommendations \\ [Related Educational Theory]}

Class was extensively supplemented with time in a computer and tutoring center staffed with instructors, graduate students, and undergraduate tutors, providing individualized support along with technology-assisted instruction. Students received constant feedback on progress with homework assignments, quizzes, and exams, keeping them on task and engaged. These supplementary methods reduced the effect size of classroom size on student achievement and satisfaction. [CoI]

Instructors' workload hours spent on discussion decreased in smaller classes. Class size was the primary effect for instructor workload. Larger class sizes impose higher time expenditure and load on instructors. Recommends optimal class size as 12 students.

With smaller classes, students feel more engaged with the material and more connected to their professor and fellow students. While students and instructors can interact in a larger class, it's challenging to have substantial interactions. A small class is a necessity in a synchronous environment since more than 15 students are too many faces on the screen. [CoI] Study discovered that students in large classes read a smaller proportion of peers' notes, and tended to scan them. Larger classes created a higher degree of information overload, encouraging coping strategies, such as scanning and selectivity in note reading. A possible consequence is shallow, superficial peer learning. [Bloom's taxonomy, CoI]

Study described developing a community of practice to share and create knowledge. Preferred learning processes involved critical thinking, problem-solving assignments, research, writing, journal reflections, discussion forums, group projects, and videoconferencing. Faculty work was teaching intensive, described as providing feedback, mentoring. Students' deeper learning marked by higher levels on Bloom's taxonomy and a constructivist pedagogy. Implied faculty use of community of inquiry practices. No specific class size recommendations.

[Objectivism-constructivism, Bloom's taxonomy, $\mathrm{COI}]$ 
One Size Does Not Fit All: Toward an Evidence-Based Framework

for Determining Online Course Enrollment Sizes in Higher Education

\section{Author(s), Date, Title,} and Journal Horning, A. (2007, Fall/Winter). The definitive article on class size. WPA, Writing Program Administration. Councils of Writing Program Administrators. Retrieved from http://wpacouncil. org/archives/31n1-2/31n12horning.pdf

Not a peer-reviewed source.

Jaggars, S. S., \& Xu, D. (2016). How do online course design features influence student performance? Computers \& Education, 95.

\section{Focus}

Article about college writing courses and class size. Author could not find a comprehensive source providing guidance, so she put together the evidence she found.

Students indicated that in writing courses, smaller classes made a difference to them. "Smaller" meant 15 or fewer students. Students viewed prompt feedback, discussing ideas with knowledgeable faculty, and individual research experiences with faculty as especially valuable to their learning, all of which required smaller classes.

Study aimed to establish a clear link between specific online course design features and concrete, studentlevel course outcomes in a community college context. Examined course organization and presentation, learning objectives and assessments, interpersonal interaction, and use of technology. Participants included 19 faculty who taught 35 course sections and 678 students during spring 2011.

Jahang, N., Nielsen, W., \& Chan, E. (2010). Collaborative learning in an online course: A comparison of communication patterns in small and whole group activities. Journal of Distance Education, 24(2). Johnson, I. (2010). Class size and student performance at a public research university: A crossclassified model. Research in Higher Education, 51(8).

Jones, S. H. (2015). Benefits and challenges of online education for clinical social work: Three examples. Clinical Social Work Journal, 43(2).
Research question: How is student communication behavior in small-group activity different from that in large-group discussions? Study was built on CoI framework.

Used data on grade performance from undergraduate class sections across all disciplinary areas at a single institution. Study controlled for student characteristics, class level, and random effects.

Three examples of fully online courses offered to clinical social work students by an experienced clinician and online instructor were examined in the context of the benefits and challenges put forth for teaching clinical content and skills online. Saw differences existing in quality and quantity of interaction and skill development. Particular attention paid to effectiveness of learning practice skills solely in this format.

\section{Recommendations \\ [Related Educational Theory]}

Three national umbrella organizations for teachers of English took a position that no more than 20 students should be permitted in any writing class, and ideally, classes should be limited to 15 (smaller for remedial sections). But college administrators largely chose to ignore these recommendations because English classes were revenue generators for schools. Cites study by Arizona State Univ. that lowered its UG English and math class sizes to 19 or fewer. Results showed improvements in students' success with higher pass rates in targeted courses, higher retention, and lower numbers of students who withdrew from or failed courses. [Objectivismconstructivism, $\mathrm{CoI}]$

Found that only the quality of interpersonal interaction between students and faculty related positively and significantly to student grades. Positive instructor influences included posting frequency, inviting student questions, responding to student queries quickly, soliciting and incorporating student feedback, and demonstrating a sense of caring. In spite of call for high teacher interaction levels, authors made no specific class size recommendations. [CoI] Students were more uniformly active, cognitively engaged, and equal participants in smaller groups. No specific class size recommendations. [CoI]

Study provided consistent evidence of a negative effect of class size on grade performance, most substantially affecting the achievement of "A" grades. In settings where outstanding student performance is the institutional goal, results suggest that classes should be reduced in size. No specific class size recommendations.

Found that online courses which are strategically and rigorously developed are comparable to face-to-face courses in many ways, including activities, assignments, assessments, outcomes, student quality, and methods of addressing academic dishonesty. Quality required robust interactions. Course prep and delivery involved significantly more time than that for face-to-face courses. Class sizes ranged from 16 to 25 . Recommended a class size of 25-35 for online courses and smaller sections for practice skills courses; online advanced clinical skills courses need smaller classes. [Objectivism-constructivism, CoI] 
One Size Does Not Fit All: Toward an Evidence-Based Framework

for Determining Online Course Enrollment Sizes in Higher Education

\section{Author(s), Date, Title,} and Journal

Kim, J. (2013, March). Influence of group size on students' participation in online discussion forums. Computers \& Education, 62 .

Kingma, B., \& Keefe, S. (2006). An analysis of the virtual classroom: Does size matter? Do residencies make a difference? Should you hire that instructional designer? Journal of Education for Library and Information Science, 47(2). Lai, K. (2015). Knowledge construction in online learning communities: A case study of a doctoral course. Studies in Higher Education, 40(4).

Lee, S., Dapremont, J., \& Sasser, J. (2011). Nursing students' perception of class size and its impact on test performance: A pilot study. Journal of Nursing Education, 50(12).

Liu, O. L. (2012). Student evaluation of instruction: In the new paradigm of distance education. Research in Higher Education, 53(4).

Mandel, P., \& Sussmuth, B. (2011). Size matters. The relevance and Hicksian surplus of preferred college class size. Economics of Education Review, $30(5)$.

\section{Focus}

Study examined one course and how students participated and interacted in different discussion modules organized with different group sizes. Students expect and were expected to develop cognitive and metacognitive skills and knowledge. If the main purpose for discussion is to have students achieve a higher level of understanding and attitude of inquiry, smaller classes needed. Based on constructivist pedagogy.

Examined the impact of enrollment, faculty teaching experience, online faculty pedagogical training, and help from an instructional designer on student course evaluations in a master's-level course. Studied traditional classroom-based and online courses.

Study was undertaken to investigate the extent of knowledge construction in an online EdD program, and how pedagogical practices affected the knowledge construction process. Focused on higher order learning and the social construction of knowledge in online discussions. Analysis, synthesis, and the evaluation levels of Bloom's taxonomy and use of the $\mathrm{CoI}$ were central to the conduct of the course.

A combination of increasing student enrollment in BSN nursing programs and the faculty shortage contribute to larger class sizes that may affect both student satisfaction and learning. Purpose of this study was to identify undergraduate nursing students' satisfaction with enrollment and subsequent test scores in small and large medical-surgical nursing courses. Courses were face-to-face with 110 students in the sample. Level of learning in the lower half of Bloom's taxonomy.

Study investigated the factors that impacted student evaluation of instruction in distance education; used a large sample of 11,351 students taught by 1,522 instructors from 29 colleges and universities. Teaching methods not addressed.

Examined the impact of class size on student evaluations of 299 instructors' performance using a sample of 1,438 economics classes held at a European university over 10 years. Controlled for course and instructor effects. Class size variation of 1-19, 20-39, 40-59, 60-79, 80-99, 100-149, and 150-200 students.

\section{Recommendations \\ [Related Educational Theory]}

Found significant differences between large and small groups in quality of postings (level of understanding, inquiry) and interactivity with peers. Two small-group discussion forums had a higher number (by $21 \%$ ) of responsive interaction in elaborating and negotiating modes. Large discussion forums had limitations in interactivity and complexity. Larger groups' postings had a greater tendency to be fragmented, not linked to peers' comments. [Objectivism-constructivism, Bloom's taxonomy, CoI]

Mean evaluations were higher for courses with enrollments of 15-25 students than for courses with lower or higher enrollments. Classes larger than 40 resulted in lower student satisfaction with the course, the level of instructor interactivity, instructor evaluations of student progress, and the intellectual content of the course. [Bloom's taxonomy, $\mathrm{CoI}$ ]

To build students' knowledge construction, design of the learning tasks drew on faculty teaching presence: creating a learning community, active facilitation and moderation of online discussions, and direct instruction. Class size of 12 students. High online teacher engagement in the course. [Objectivismconstructivism, Bloom's taxonomy, $\mathrm{CoI}]$

Mixed results: indicated that students in the smaller class had significantly higher satisfaction with having adequate time for classroom discussion, a classroom setting providing an environment that allowed for effective socialization with other students and faculty, and that the number of students enrolled in the course positively affected how they learned the material. No significant difference between test scores of students enrolled in the large vs. small classes. Large class was 98, small class 58. [Bloom's taxonomy, CoI] Found that class size had no impact on students' evaluation of instruction. Researchers felt that students could actively participate in online discussions if they were willing to, regardless of how many students were taking the class. No specific class sizes identified.

Found a substantial reduction in mean evaluation scores as class size rose from 1-19 to 20-39 (i.e., a profound threshold effect at a maximum class size of 19). Class sizes $>20$ meant an instructor barely knew her students by name, and the course lost its "hands-on" character. Authors noted that it is reasonable to expect a change in pedagogical practices - from more active and engaged to impersonal - at a demarcation point of 19 students. [Objectivism-constructivism, CoI] 
One Size Does Not Fit All: Toward an Evidence-Based Framework

for Determining Online Course Enrollment Sizes in Higher Education

\section{Author(s), Date, Title,} and Journal

Maringe, F. \& Sing, N. (2014). Teaching large classes in an increasingly internationalising higher education environment: Pedagogical, quality and equity issues. Higher Education: The International Journal of Higher Education and Educational Planning, 67(6).

\section{Focus}

Diversity in classrooms requires smaller classes to account for differentials in backgrounds, prior knowledge, and language and writing skills. Commonly used to prepare students both conceptually and practically for university learning, large classes ( $>100$ students) are aimed at providing foundation-level learning (i.e., lecture- and testingcentered pedagogy that emphasizes memory and regurgitation of knowledge), viewed as surface learning. Using Bloom's taxonomy as a framework of analysis, researchers noted that the larger a class is, the greater the chances that students engage at the lower levels of abstraction. Focus is on UG students. Authors state that the case for large classes in higher education is justified primarily on economic grounds.

Mbati, L., \& Minnaar, A. (2015). Guidelines towards the facilitation of interactive online learning programmes in higher education. International Review of Research in Open and Distributed Learning, 16(2).
Authors indicated that the use of technologies for teaching and learning requires sound content specialization and understanding of learning theories to guide pedagogy. While gains made by

constructivism and observational learning are well documented, research addressing online practices that best encourage constructivist and observational learning in distance contexts is limited.
Means, B., Toyama, Y., Murphy, R., Bakia, M., \& Jones, K., Office of Planning, Evaluation, and Policy Development, Policy and Program Studies Service: US Department of Education. (2010). Evaluation of evidence based practices in online learning: A meta-analysis and review of online learning studies.
Research provided a systematic search of the literature 1996-2008, identifying empirical studies of online learning. Sought to identify studies that contrasted an online to a face-to-face condition and measured student learning outcomes.

Described three types of learning experience:

- Expository instruction-Digital devices transmit knowledge (information).

- Active learning - The learner builds knowledge through inquiry-based manipulation of digital artifacts, such as online drills, simulations, games, or microworlds.

- Interactive learning-The learner builds knowledge through inquiry-based collaborative interaction with other learners; teachers become co-learners and act as facilitators.

\section{Recommendations \\ [Related Educational Theory]}

Provides extensive evidence for small classes with diverse student groups, which yield higher academic achievement, aspirations, and critical thinking. Deep learning only happens in smaller classes; students who learn in small classes consistently outperform those in large classes. Large size limits personalized feedback and reduces both quantity and quality of curriculum coverage and assessment. Students in large classes demonstrate low-level learning: low engagement, question asking and interaction, and critical thinking. Found that in small classes with $\leq$ 15 students, abstraction was more at the analysis level. In larger classes (16-45), students abstracted at the comprehension level, while those in classes $\geq 46$ tended to abstract at the factual recall level.

[Objectivism-constructivism, Bloom's taxonomy, $\mathrm{CoI}]$

Researchers identified 4 constructivist criteria: (1) eliciting of prior knowledge; (2) creation of cognitive dissonance, when the student is made aware of the difference between his or her prior and new knowledge; (3) student application of knowledge, with feedback: student interprets and modifies prior knowledge in the context of new knowledge; and (4) student reflects on learning, integrating the new knowledge permanently. Constructivist pedagogy requires small student-facilitator ratios. [Objectivismconstructivism]

Largest finding was the equivalency (or better) of learning from online courses vs. face-to-face; blended learning was found to be more effective than both.

The practice with the strongest evidence of effectiveness was inclusion of mechanisms to prompt students to reflect on their level of understanding as they are learning online. Relatedly, there was some evidence that online learning environments with the capacity to individualize instruction to a learner's specific needs improved effectiveness. Independent online learning was found less effective. [CoI] 
One Size Does Not Fit All: Toward an Evidence-Based Framework

for Determining Online Course Enrollment Sizes in Higher Education

\section{Author(s), Date, Title,} and Journal

Monks, J., \& Schmidt, R. M. (2011). The impact of class size on outcomes in higher education. The BE Journal of Economic Analysis and Policy, 11(1).

\section{Focus}

To estimate the class size direct effects on courses taught over 12 years, this study utilized a natural experiment-a unique policy change about class sizes within a business school - at a single private university; controlled for faculty and course effects. The sample included 48 individual faculty members, 88 separate courses, and 1,928 course sections. Courses with 2-45 students (mean of 23.39) were compared with those holding an average of 13.4 more students.

Morse, R., Brooks, E., \& Mason, M. (2018). How U.S. News calculated the 2019 best colleges rankings. Retrieved from https://www.usnews.com/educati on/best-colleges/articles/how-usnews-calculated-the-rankings

Mupinga, D. M., \& Maughan, G. R. (2008). Web-based instruction and community college faculty workload. College Teaching, 56(1).

Not a study; authors sought benchmarking data from like institutions.

Palmer, S., \& Smith, C. (2013). Updating RIGs: Including the systematic influence of online study on student evaluation of teaching. Educational Research and Evaluation, 19(1).
U.S. News and World Report College Rankings based on up to 16 measures of quality in 6 categories: Outcomes (35\%); Faculty Resources (20\%); Expert Opinion (20\%); Financial Resources (10\%); Student Excellence (10\%); and Alumni Giving (5\%). A measure of class size counts for $50 \%$ of Faculty Resources, which itself contributes $20 \%$ to the overall ranking.

The authors examined the workload for faculty teaching online courses in community colleges, specifically, the number of online classes taught per semester, class sizes for online courses, incentives for online instructors, and how the workload for online instructors is calculated. In community colleges, faculty workload commonly refers to the number of hours spent in the classroom each week times the number of students enrolled.

At a single university, researchers studied the influence of class size, year level, and discipline area on student evaluations of teaching (SET ratings) over a year and across disciplines.

Note: Class sizes were $<51,51-100$, and $>100$. All of these would be considered "large" by distance learning literature standards.
Parks-Stamm, E. J., Zafonte, M., \& Palenque, S. M. (2016, September). The effects of instructor participation and class size on student participation in an online class discussion forum. British Journal of Educational Technology.
Study from a single university in the southwest United States; analyzed the frequency of instructor and student posts in asynchronous discussion forums in online courses to examine factors contributing to student participation. Sampled 500 courses: 250 undergraduate and 250 graduate (189 masters level, 61 doctoral) containing 6,954 students. Authors defined class sizes as small $(<15)$, medium (15-34), and large $(>34)$.

\section{Recommendations \\ [Related Educational Theory]}

Found that class size negatively and significantly influenced course outcomes: The larger the section size, the lower the self-reported learning, the instructor rating, and the course rating. Students rated instructors lower in clarity of presentations, effectiveness of teaching methods, daily preparedness, effectiveness in stimulating interest, enthusiasm for teaching the class, and adequacy of graded material relative to course content. Also negative but nonsignificant: critical thinking, availability of the instructor, respect the instructor had for students, and timeliness of feedback. [CoI]

Class size is the most highly weighted measure of the Faculty Resources category. Class size is scored as the proportion of undergraduate classes with fewer than 20 students (highest level of credit); 20-29 students (second highest level of credit); 30-39 students (medium level of credit); 40-49 students (second lowest level of credit); and 50-plus students (no credit).

Results from these authors indicated inconsistent practices within and between institutions. For example, the workload for online instructors based on class sizes could be less than, equal to, or more than that of faculty teaching face-to-face courses. Variations in online-class sizes were $20-50$, with a mode of 25. Article notes that even the AAUP acknowledges the difficulty of devising a single formula for equitable workloads in higher education. Found that increasing class sizes yielded significantly lower mean SET ratings. Magnitudes of effect sizes were small but potentially cumulative. Most of the SET items found to be negatively influenced by class size (e.g., helpful feedback, academic challenge) were those relating to student academic engagement with their studies. Findings seemed to indicate that students in online mode notice the absence of personal communication or attention that a teacher can give, the "teacherly" aspects of their studies. [CoI]

Class sizes ranged from 2 to 30 students, with a median of 15 students per class. Study found a significant impact of instructor participation on student participation, which decreased as class size increased. Instructors' participation positively predicted student participation especially in small classes $(<15)$, i.e., with high-participating faculty, students interacted more. But in medium classes (1530 students), amount of instructor participation did not predict the number of posts per student. [CoI] 
One Size Does Not Fit All: Toward an Evidence-Based Framework

for Determining Online Course Enrollment Sizes in Higher Education

\section{Author(s), Date, Title,} and Journal

Qiu, M., Hewitt, J., \& Brett, C. (2012). Online class size, note reading, note writing and collaborative discourse.

International Journal of

Computer-Supported

Collaborative Learning, 7(3).

Ravenna, G. (2012). The effects

of increased workloads on online instruction. International Journal of Education, 4(4).

Article is a report not based on original research.

Roby, T., Ashe, S., Singh, N., \& Clark, C. (2013, April). Shaping the online experience: How administrators can influence student and instructor perceptions through policy and practice. Internet and Higher Education, 17.

Russell, B. H. (2015). The who, what, and how of evaluation within online nursing education: State of the science. Journal of Nursing Education, 54(1).

\section{Focus}

Study examined relationships among class size, note reading, note writing, and collaborative discourse by analyzing tracking logs from 25 graduate-level online courses ( 25 instructors and 341 students) and interviews with 10 instructors and 12 graduate students. Class sizes in this study ranged from 6 to 22 . Authors indicated that appropriate class sizes should be set in order to ensure for each class a minimum critical mass for participation - without overload - to reach the goals associated with collaborative learning, encourage greater interactivity, and to make it easier to establish social presence.

Paper discussed budget cuts for California State University that created significant workload increases for instructors. Author used the CoI with an emphasis on teaching presence as a framework for report.

Author examined the state of the science around the current evaluation of educational practices, instructional strategies, and outcomes within the context of online nursing education. Study used 36 articles published between 2008 and 2013 that met the inclusion criteria. enhance student and instructor experiences in online environments. Surveyed students about their perceptions of the online and blended courses that they participated in, and surveyed instructors about online and blended courses that they taught.

\section{Recommendations \\ [Related Educational Theory]}

Findings: Class size was a major factor affecting note reading and writing loads. Class size was found negatively correlated with the percentage of notes students read, their note size, and note grade level score. In larger classes, participants were more likely to experience information overload and therefore were more selective in reading peers' notes. Findings suggested 13-15 as an optimal class size. A graduatelevel class of 18 or more would make a single conversation difficult and would become overwhelming and less manageable for both students and instructors. [CoI]

As class sizes increase, faculty have more papers to grade; less direct contact with students, and more students engaged in discussions; faculty's ability to individualize instruction decreases. Hence, the quality of education declines with expanding class sizes.

Deeper learning requires more student-instructor interaction and smaller class sizes, while classes that require less higher order thinking may suffice with larger numbers. [Objectivism-constructivism, Bloom's taxonomy, CoI]

Purpose of the study was to identify factors that would Re: class size: $78 \%$ of instructors indicated ideal class

sizes as up to 30 students. Students were less impacted by larger classes, with $69 \%$ indicating up to 50 students. However, some students were discontented with a lack of instructor availability and slow response times to questions; instructors reported being time challenged by the amount of student monitoring, facilitating, tracking, and grading required with online teaching. [CoI]

Findings reflected online education evaluation practices that were diffuse and superficial, and served as the basis for recommendations and future research. Among others, article recommends concepts of constructivism, Bloom's taxonomy, and the CoI model. Recommended nursing literature include cross-disciplinary views of best practices in online education. [Objectivism-constructivism, Bloom's taxonomy, $\mathrm{CoI}]$ 
One Size Does Not Fit All: Toward an Evidence-Based Framework

for Determining Online Course Enrollment Sizes in Higher Education

Author(s), Date, Title, and Journal

Focus

Russell, V., \& Curtis, W. (2013, Study explored how class size affected the quality of January). Comparing a large- and undergraduate online language teaching and small-scale online language course: An examination of teacher and learner perceptions. Internet and Higher Education, 16.

Salley, W., \& Shaw, M. (2015). Employment status, teaching load, and student performance in online community college courses. Online Journal of Distance Learning Administration, 18(2).

Schwartz, M. (2014). KHAN Academy: The illusion of understanding. Journal of Asynchronous Learning Networks, 17(4).

learning. Research compared the experiences of instructors and students in 2 online Spanish language courses: 125 students enrolled in the large-scale class and 25 students enrolled in the small-scale class. Each class had one instructor and no teaching assistants.

The American Council on the Teaching of Foreign Languages' (ACTFL) 2010 position statement on class size recommended that language courses offered either in a traditional classroom or at a distance should be capped at 15 students, which is in alignment with the National Education Association and the Association of Departments of Foreign Languages (ADFL) 2010 recommendations for maximum class size.

Study was conducted at a community college in the Midwest and addressed 3 issues: (1) overextended online instructors in the local setting with a consequent inability to implement best practices; overextended online instructors may not offer the presence and feedback needed to promote success in online student performance, as measured by final overload teaching assignments; and (3) increased teaching loads could have negative ramifications for online instructor attentiveness, student performance, and academic rigor.

Paper examines what learning means from the perspective of the cognitive and learning sciences. Using Khan Academy as an example of limited educational value, author applies learning theory to online environments. Provides a framework for course grades; (2) the institutional system encouraged authentic (deep) understanding: Authentic understanding depends on hierarchically organized knowledge, requires formative feedback for student development, and is context sensitive, grounded in direct experience and stabilized by practice at every level within the hierarchy.

Seaton, J. X., \& Schwier, R. (2014). An exploratory case study of online instructors: Factors associated with instructor engagement. International Journal of E-Learning \& Distance Education, 29(1). the experiences of 12 online instructors were examined over 1 year. Participant interviews were analyzed for evidence of positive and negative experiences and how frequently each occurred.
This research was an exploratory case study in which

\section{Recommendations \\ [Related Educational Theory]}

Results indicated that a large class negatively impacted course quality and students' satisfaction with their online language learning experience. In the large-scale course, the quality and quantity of studentstudent and student-instructor interaction were limited, and since the large size affected the instructor's ability to create an environment conducive to learning, instructor expertise was underutilized.

Both faculty and students indicated instructors could not provide sufficient feedback for achieving learning goals.

Administrators and departments often make decisions about class size based on fiscal and budgetary constraints rather than on best practices in blended and/or online learning. [Objectivismconstructivism, $\mathrm{CoI}]$

A negative correlation was discovered between instructor course overload and student success as measured by final course grades and completion rates. Because online teaching presence is a key factor to student success, smaller classes would allow faculty to spend more time with each student. Faculty loads should be carefully monitored to ensure the highest possible rates of student success. [CoI]

Author describes educational systems that are and historically have been mostly didactic, with Khan Academy as a prominent online example. Didactic delivery fails to provide scaffolding experiences, student feedback, and conceptual mastery that allow learners to build deep understandings of complex phenomena. To promote student development and enable the agile transfer of student learning to new contexts, author urges a shift of perspective to focused teaching methods, constructivist pedagogy, and higher order learning. Does not address class size-focus is on pedagogy. [Objectivism-constructivism, Bloom's taxonomy, $\mathrm{CoI}]$

Specific barriers to online faculty engagement included an increase in workload, technological issues, and lack of social presence. Instructors hired to teach and conduct research held mixed and often negative feelings about teaching in online environments. Class sizes varied from 15 to $>50$. There was a slight difference in faculty engagement between smaller classes and those over 50, but this finding was not significant. [CoI] 
One Size Does Not Fit All: Toward an Evidence-Based Framework

for Determining Online Course Enrollment Sizes in Higher Education

\section{Author(s), Date, Title,} and Journal

Shaw, R-S. (2013). The relationships among group size, participation, and performance of programming language learning supported with online forums. Computers \& Education, 62.

Sorensen, C. (2014, December). Class-rooms without walls: A comparison of instructor performance in online courses differing in class size. MERLOT Journal of Online Learning and Teaching, 10(4). and

Sorensen, C. (2015). An examination of the relationship between online class size and instructor performance. Journal of Educators Online, 12(1).

Sword, T. S. (2012). The transition to online teaching as experienced by nurse educators. Nursing Education Perspectives, 33(4).

Taft, S. H., Perkowski, T., \& Martin, L. S. (2011). A framework for evaluating class size in online education. Quarterly Review of Distance Education, 12(3).

\section{Focus}

This study examined the relationships among group size, participation, and learning performance factors of sophomores when learning a programming language in an online collaborative learning (CSCL) context. Capitalizing on the sharing of goals, authority, and responsibility among members and individual differences in abilities, collaborative learning involved intragroup learning via focused group discussions. Study compared learning performance among and between groups; all had the same instructor and educational materials; each group used a forum to discuss 10 programming exercises. There were 120 students in the 2 courses with 2-6 students in 15 small groups and 60 in a large class. The purpose of this study was to look at instructors' performance teaching online courses and how class size influenced their performance, measured through peer reviews and scoring of online faculty in 5 areas: fostering critical thinking, providing instructive feedback (CoI teaching presence), maintaining high expectations, establishing relationships (social presence), and exemplifying instructor expertise (CoI teaching presence). Used data collected during a 2013 peer review of 380 part-time online instructors within a college of education at a large for-profit university. The courses were reviewed and scored by full-time faculty and consisted of both undergraduate and graduate courses (217 and 163 respectively).

Nurse educator participants were asked to share their lived experiences of the transition from teaching in a classroom setting to online delivery.

Study explored the question of optimal online class sizes by reviewing multidisciplinary education research journals to determine what, if any, guidance on class size existed. Research to date offered no consensus regarding appropriate student-to-teacher ratios in online courses. Further research was recommended to assess student learning outcomes across courses of varying size.

\section{Recommendations \\ [Related Educational Theory]}

Results showed that (1) the online forum support aided collaborative learning, regardless of group size; (2) group sizes did not significantly influence learning scores directly but significantly influenced participation; small groups had higher participation rates, which positively influenced learning scores; and (3) learning satisfaction using the online forum was higher than the average score. Participation did not significantly influence learning satisfaction, but small groups had higher learning satisfaction rates. Author recommends instructional designs with small groups for learning in online forums. [CoI]

Author asserted that more time per student is needed to teach online courses. Classes were categorized into three sizes: $1=$ classes with 10 students or less (small), 2 = classes with 11-19 students (medium), and 3 = classes with 20-30 students (large). Statistically significant results from this study revealed that larger class sizes potentially had the most negative effect on instructors' ability to use their expertise, establish relationships, and share knowledge of subject matter. Sharing expertise and providing student feedback are key practices to support student learning. Although not statistically significant, negative correlations suggested that as class size increased, instructors' overall teacher performance, a peer review score, decreased.

[Objectivism-constructivism, $\mathrm{CoI}$ ]

The predominant theme, expressed strongly by participants, was the amount of time needed to teach online ("double my time"). Issue links to class size and faculty workload, but these themes were not developed.

Authors proposed the use of three educational frameworks to guide class enrollment decisions while maintaining educational quality: Bloom's taxonomy, objectivist-constructivist teaching strategies, and the CoI model. Proposed setting student numbers for categorizing class size: small: $\leq$ 15 students; medium: 16-30 students; large: $\geq 30$-no known upper limit of students. [Objectivismconstructivism, Bloom's taxonomy, $\mathrm{CoI}]$ 
One Size Does Not Fit All: Toward an Evidence-Based Framework

for Determining Online Course Enrollment Sizes in Higher Education

Author(s), Date, Title, and Journal Tynan, B., Ryan, Y., \& LamontMills, A. (2015, January). Examining workload models in online and blended teaching. British Journal of Educational Technology, 46(1).

Walls, J. K. (2016). A theoretically grounded framework for integrating the scholarship of teaching and learning. Journal of the Scholarship of Teaching and Learning, 16(2).

\section{Focus}

Paper reports on a research project in 4 Australian universities, and the perceptions of a representative group of 25 academic staff from each of the universities who perceived that e-teaching had increased their "teaching time" workload. Workload Allocation Models (WAMs) did not take account of contemporary teaching modalities. A search of the international literature indicated there is limited rigorous research that points to the actual effects of online and blended higher education teaching environments on workload. Interactive learning models and constructivist pedagogies should be considered routine.

Article addresses the importance and utility of teaching from a guiding theoretical framework; discusses Bronfenbrenner's bioecological model as an interdisciplinary framework for synthesizing the scholarship of teaching and learning to inform faculty at the college level. Human development, a process that occurs as a joint function of characteristics of the individual and environmental context, has 4 components: process, person, context, and time.

\section{Recommendations \\ [Related Educational Theory]}

Australian WAMs do not account for the increased number, complexity, variability, and intensity of teaching/communication tasks associated with online learning. Student numbers per section is often arbitrarily determined by administrators - in Australia, typically 40 per section. Authors urge a rethinking of the models of delivery, pedagogies and activities associated with e-learning, workload implications, and a refocus on desired outcomes rather than input models of "one-size-fits-all." WAMs must be developed that recognize headcount as the determinant of load per class. [Objectivismconstructivism, $\mathrm{CoI}]$

Central to the bioecological model are proximal processes, or the regular interactions that occur between the developing person and his or her environment. Proximal processes are the driving forces behind student development, emphasizing that interactions (e.g., faculty-student, student-student) needed to occur on a regular basis and become increasingly complex over time in order to promote development. As part of context dimension, author sees larger class sizes as linked to poorer student and teacher performance, which suggests that teaching and learning challenges increase in proportion to the number of students in a given class. No specific class size recommendations. [Objectivism-constructivism, $\mathrm{CoI}]$

A 2011 article examining pedagogy provided insight on how online class sizes affect student learning. It reported on a multidisciplinary literature review of relevant research articles from 17 journals published between 2000 and 2009 (Taft et al., 2011). The researchers aimed to distinguish factors found to drive optimal student learning that could serve to guide decisions on appropriate enrollments. Drawing from studies in different settings, the researchers looked for accumulated evidence that identified the impact of various online enrollment numbers on student learning outcomes, faculty workload, and student satisfaction. The article included an unsuccessful search for measurement tools and/or evaluation criteria to assess varying class sizes' influence on student learning. Among the studies identified and reviewed, the then-existing evidence on class size was found to be limited and plagued by conflicting results. Findings reported inconsistent online class size recommendations that ranged from four to several hundred students, results that were insufficient to support enrollment recommendations. However this study's literature review provided the researchers with specific learning theories relevant to student education that they proposed as guidelines for online class size determinations.

The three well-established learning theories in the literature described were repeatedly referenced and linked to class size implications: the objectivist-constructivist continuum, Bloom's taxonomy, and the Community of Inquiry model (Taft et al., 2011). For the current study, we updated the research review to 2017 and greatly expanded the journal search. We explored whether the three learning theories were identifiable in the reviewed literature and found that they were 
explicitly or implicitly prominent in most relevant studies. The theories are summarized below and will provide the foundation for categorizing and synthesizing our findings. Expanded theory descriptions and references are profiled in Appendix B.

\section{Three Learning Theories}

This section presents the three learning theories connected to student learning and class size effects used in the 2011 study. Appendices A and B provide reference links of these theories to the current literature review.

The objectivist-constructivist continuum. Objectivist-constructivist theory is a wellestablished construct in pedagogical methods differentiating two ends of a continuum. On the objectivist end of the continuum, students are expected to learn relatively passively by receiving and assimilating knowledge communicated to them by a professor. Objectivist pedagogy largely uses teacher-centered one-way communication; students learn individually, independently from one another, and then are tested for evidence of learning. This approach effectively delivers and teaches content of a factual or basic scientific nature.

On the other end of the continuum, the constructivist teaching method facilitates learning of a more complex nature via thoughtful interactions among students and faculty and with course content. Constructivist learning environments offer multiple representations of reality by encouraging student reflections on their own and others' understandings, and how they compare or contrast (Arbaugh \& Benbunan-Fich, 2006). Constructivism suggests that as students confront new information, they compare it to preexisting "internalized knowledge constructs based on [their] past experiences, and then modify their constructs accordingly ... Knowledge has to be discovered, constructed, practiced, and validated by each learner" (Benbunan-Fich et al., 2005, p. 21). Constructivist learning is student centered, requiring that students utilize critical thinking by breaking down, restructuring, and transforming preexisting knowledge to build new conceptions of understanding. Discussion and dialogue are central to promoting critical thinking.

Faculty workload using constructivist teaching methods expands directly in relation to the number of enrolled students-it is teaching-intensive. Some researchers argue that as class sizes rise above $\sim 20$ students, it is implicitly reasonable for faculty to reduce their workload by changing pedagogical practices, from more active and engaged constructivism to less individualized approaches (Benton \& Pallett, 2013; Colwell \& Jenks, 2004; Goldman, 2012; Horning, 2007; Mandel \& Sussmuth, 2011).

University faculty select teaching approaches that fall somewhere on the continuum between transmitting knowledge to students unidirectionally to engaging them in creating meaningful knowledge development from new information (Taft et al., 2011). In online education, the choice of teaching method along the objectivist-constructivist spectrum has a direct relationship to the number of students enrolled in a course. Further elaboration of this theory, the next two theories, and author sources are presented in Table 2 . 
One Size Does Not Fit All: Toward an Evidence-Based Framework

for Determining Online Course Enrollment Sizes in Higher Education

Table 2.

Elaborated Description of Three Learning Theories-Objectivism-Constructivism, Bloom's Taxonomy, and the Community of Inquiry - and a Case Example

\section{Theory Description}

Objectivist-constructivist pedagogy is an established construct in education and pedagogy.

Objectivist pedagogy is a teacher-centered process used to transmit factual content. It employs test-based or quantifiable assessment methods; assumes that students will generally learn equally well if they are in a class of 5 or 500 . While the workload for faculty will expand modestly with rising numbers of students, it does not increase directly with class size.

Because research reveals no recognized upper limit to the number of students enrolled per faculty member in objectivist-taught courses, class sizes may be as large as is logistically feasible.

Conversely, because it is learner-centered, a constructivist approach requires smaller class sizes. The student work of learning - deconstructing old knowledge and integrating new and more complex information-depends on faculty interaction with individuals and groups of students, regular individual instruction, correction of misconceptions, formative and summative feedback, and assessments to measure learning progress.

Constructivist educators approach teaching with the belief that knowledge must be actively reasoned and created by students to effectively integrate knowledge frameworks. Few students are capable of complex learning without focused facilitation from knowledgeable experts.

Bloom's taxonomy: A classic in education theory, categories of learning level align in a pyramid, from simple/concrete (lower levels) to complex/abstract (higher levels). Each category contains subcategories. Knowledge at the lower levels is the necessary precondition for higher level understanding and putting skills and abilities into practice.

The original taxonomy from 1956 proposed 6 levels:

1. Knowledge: the recall of specifics and universals, methods and processes, or patterns, structures, or settings

2. Comprehension: an understanding or apprehension such that an individual fathoms what is being communicated and can make use of the ideas without necessarily seeing their fullest implications

3. Application: the ability to use and apply abstractions to particular situations

4. Analysis: the breakdown of information into its constituent parts such that the relative hierarchy of ideas is clear or the relationships between ideas are explicit 5. Synthesis: integrating elements and parts so as to form a whole

6. Evaluation: forming judgments about the value of materials and methods for specific purposes

The revised taxonomy (2001) added Level 7:

7. Creation: generating, developing, designing, planning, or producing

\section{Sources}

Arbaugh \& Benbunan-Fich, 2005; Bain, 2004; Benbunan-Fich et al., 2005; Benton \& Pallett, 2013; Bozkurt et al., 2015; Chu, Zhang, Chen, Chan, Lee, Zou, \& Lau, 2017; Curriculum Committee, 2012; El Tantawi, Abdelsalem, Mourady, \& Elrifae, 2015; Holtslander, Racine, Furniss, Burles, \& Turner, 2012; Holzweiss et al., 2014; Jones, 2015; Kim, 2013; Lai, 2015; Legg, Adelman, \& Levitt, 2009; Mandel \& Sussmuth, 2011; Maringe \& Sing, 2014; Mbati \& Minnaar, 2015; Picciano, 2017; Ravenna, 2012; Russell, 2015; Schellens \& Valcke, 2006; Schwartz, 2014; Taft et al., 2011; Williams, Jaramillo, \& Pesko, 2015

Armstrong, n.d.; Benton \& Pallett, 2013; Bloom et al., 1956;

Holzweiss et al., 2014; Lai, 2015; Meyer, 2006; Ravenna, 2012; Russell, 2015; Taft et al., 2011 
One Size Does Not Fit All: Toward an Evidence-Based Framework

for Determining Online Course Enrollment Sizes in Higher Education

\section{Theory Description}

Use of the CoI model enhances student learning and satisfaction. Numerous studies have confirmed the value of the CoI. The CoI describes 3 presences: Teaching/teacher presence: involves the design, facilitation, and direction of learning to serve students' constructions of meaningful and educationally worthwhile knowledge. Teaching presence is conceptualized as instructional design and organization, facilitating discourse, building understanding, and direct instruction.

Extensive activities are associated with a full teaching presence, ranging across developing the course design, syllabus, learning strategies, and activities; engaging in regular authentic interactions with individuals and groups of students; and providing individualized formative and summative feedback. Cognitive presence marks the extent to which students demonstrate construction and integration of new meaning through sustained learning activities. When assignments require critical thinking via student explanations or applications, student knowledge construction is visible in the online classroom. In CoI theory, students' cognitive presence is influenced by the faculty's teaching and social presences and by other students' cognitive and social presences. Faculty teaching presence diminishes students' internalized barriers to learning new information while aiding construction of new meanings.

Social presence is reflected in the ability of faculty and learners to project themselves socially and emotionally into a course, and, in the online environment, create an identity as a "real person." A student's social presence is affected by the faculty's teaching and social presence, and by other students' cognitive and social presence. In CoI theory, teacher immediacy, referring to "behaviors that lessen the psychological distance between communicators" (Swan \& Shea, 2005, p. 242), is a recognized driver of student learning and satisfaction. It can include a range of faculty social actions such as prompt and focused replies, warmth and friendliness, addressing students individually, use of humor or emotion, self-disclosure, greetings and closures, and connecting language (Lahaie, 2007).

Case example of a course appropriate for constructivist pedagogy, application level and above on Bloom's taxonomy, and use of the Col's teaching, cognitive, and social presences:

One of the authors of this article was involved in the teaching of graduate nursing students in an advanced applied clinical pharmacology course. While students entering the course could pass exams testing for knowledge of the physiological action of various classes of drugs, their existing knowledge was insufficient to directly translate that knowledge to caring for real patients (e.g., patients who might be elderly, compromised by a set of chronic diseases, and ingesting prescriptions for 10 or more potentially inter-/counteractive drugs). Faculty needed to draw upon professional and scholarly expertise to lead students through a thinking process of sorting treatment priorities, comparing trade-offs, estimating risks, and factoring in costs while directing care decisions that kept patients' and families' priorities at the forefront-that is, clinical reasoning that served complex patients. Developing higher order thinking was the central learning purpose of the pharmacology course in that students' mastery of a hierarchy of organized knowledge would provide them with a structure for future clinical decision-making. 
In teaching-intensive constructivist learning classes, the research indicates that the number of students is a significant driver of increased faculty workload. In courses that use a combination of objectivist and constructivist approaches to teaching - those that fall in the middle of the continuum-consideration of the mix of pedagogies for student learning and the resulting implications for a feasible faculty workload are necessary to determine the "right" number of students. Course enrollment decisions should provide a balance between student learning effectiveness, with faculty serving as pedagogical experts; faculty workload; and university revenue needs, with academic administrators speaking to finances.

In the articles reviewed for this study, researchers commonly used objectivistconstructivist terminology to describe different approaches to teaching and the results in student learning associated with them. Some of the articles used descriptive language consistent with objectivism-constructivism and didn't identify it explicitly, but the researchers were able to infer its meaning from authors' commentary.

Bloom's taxonomy. Bloom's taxonomy is a classification of seven levels of learning moving from lower levels to higher order thinking, respectively: knowledge, comprehension, application, analysis, synthesis, evaluation, and creation (Armstrong, n.d.; Bloom [Ed.], Englehart, Furst, Hill, \& Krathwohl, 1956). It is used to structure course learning objectives, activities and assessments, and has become a classic in education theory. Course objectives targeted to various levels of Bloom's taxonomy arrange in a pyramid hierarchy, with more basic knowledge falling low and sophisticated knowledge high on the taxonomy (see Table 2). Student learning is assessed consistent with the learning level. Although there is considerable variability in targeted taxonomic levels in higher education courses, conventionally more basic knowledge and comprehension levels are addressed in lower division college courses, while more complex learning and critical thinking are expected in upper division and graduate courses (Maringe \& Sing, 2014); doctoral study disproportionately aims for mastery at the analysis, synthesis, evaluation, and creation levels (Taft et al., 2011).

As noted earlier, by historical practice universities implicitly recognize that extensive faculty-student interaction is necessary for effective learning at the upper levels of Bloom's taxonomy. Higher order thinking requires more advanced student-faculty communication, assignments, assessment methods, feedback, and guidance - and smaller course sizes.

In the studies reviewed for this article, many researchers referred explicitly to Bloom's taxonomy. Some of the articles recommending smaller classes used descriptive language consistent with Bloom but not identified as such. As with objectivism-constructivism, we inferred reference to the taxonomy from the authors' descriptions (summarized in Table 1).

The Community of Inquiry. The Community of Inquiry (CoI) is the third educational theory relevant to online class size. The CoI and constructivist pedagogy are listed, respectively, as first- and third-most-cited concepts from seven peer-reviewed distance education journals dated 2009-2013 (all seven were included in this article's journal reviews; Bozkurt et al., 2015). First developed in 2000 by Garrison et al., and later supported by the results of numerous studies, the CoI model in online education posits that the instructor's role is critical to enabling student learning. The model advances three kinds of presence - teaching/teacher, cognitive, and socialas meaningful contributors to learning effectiveness within online environments (see Table 2). They are applicable to all levels of university curricula. 
Comprehensive use of the CoI model has been consistently found to enhance student learning and satisfaction. It is relevant to class size determinations because full implementation of teaching, cognitive, and social presence behaviors involves student interaction, more frequent faculty interventions, and individualized student learning feedback and development. CoIdesigned courses are time-intensive to teach. Partial implementation of the CoI is less teaching intensive, as in courses where faculty forego elements of knowledge-building interactions, developing social presence, providing individualized instruction, or facilitating discourse. For such courses, faculty tend to use testing for student assessments and more objectivist and standardized teaching methods. As with objectivist-constructivist pedagogy and Bloom's taxonomy, some research articles reviewed for this study referred explicitly to the CoI model while others used descriptive language consistent with it.

Of the 58 selected articles reviewed for the current study, 40 implicitly or explicitly identified one or more of the three learning theories discussed above. These theories are noted for each reference [in brackets] in the third column of Table 1, under Recommendations \& Related Educational Theory. Those that did evidence use of the learning theories focused on pedagogy; educational depth, level, and quality; faculty presence; and effectiveness of student learning. Those that did not show connections with one or more of the three theories lacked study variables relevant to student learning; instead, they focused on class size associations with faculty workload, student evaluation of instruction, or used settings with preexisting small classes.

Three research questions guided the literature review for this study:

- When are small classes needed?

- When are large classes appropriate?

- What number of students constitutes a small, medium, or large class?

Based on the three learning theories reviewed above and following the next two sections on Methods and Findings, we will propose pedagogically driven class sizes and guidelines for making evidence-based enrollment decisions.

\section{Methods}

Research on online education is a multidisciplinary endeavor (Russell, 2015; Taft et al., 2011). It is based on the concepts and theories derived from the field of education, but teaching practices use concepts, principles, models, and theories from many other fields (e.g., engineering, management, sociology, psychology, economics, journalism, etc.; Bozkurt et al., 2015). Therefore, for a literature search on online class sizes, we selected higher education research journals from a variety of disciplines.

This study was designed as a more extensive literature review on class size than was reported in a 2011 review, which had included 17 education journals and 20 selected articles (Taft et al., 2011). The current systematic review comprised 43 cross-disciplinary education journals published, with a few exceptions, over a roughly five-year time frame of 2012 to 2017; earlier articles that were frequently cited were included. Journals were chosen based on their known history of publishing articles relevant to this study's purpose (see journal list in Table 3). The authors also conducted electronic keyword searches on "class size in online education" for articles listed through Education Source, Scopus, ProQuest, PsychINF, ERIC, Academic Search Complete, CINAHL, and PubMed, but these resulted in few additional sources. 
Table 3

Cross-Disciplinary Education Journals and Years Selected for Literature Review $(n=43)$

\begin{tabular}{|c|c|}
\hline $\begin{array}{l}\text { Academy of Management Learning and } \\
\text { Education 2012-2017 (Issue } 1 \text { ) }\end{array}$ & $\begin{array}{l}\text { Journal of Distance Education, 2010, 2015- } \\
2016\end{array}$ \\
\hline American Journal of Distance Education, & Journal of Higher Education, 2012-2016 \\
\hline 2012-2017 (Issue 1) & Journal of Information Systems Education, \\
\hline British Journal of Educational Tech & $2012-2016$ \\
\hline 2012-2017 (January) & Journal of Interactive Online Learning, 2012- \\
\hline Computers and Education, 2012-2017 (Vol. & 2016 \\
\hline 109) & Journal of Management Education, 2012-2017 \\
\hline Computers \& Education: Distance & (issue 2) \\
\hline Education, 2014-2016 & Journal of Nursing Education, 2012-2017 \\
\hline Distance Education, 2012-2016 & Journal of Professional Nursing, 2012-2017 \\
\hline Distance Learning, 2012-2016 & (Issue 1) \\
\hline $\begin{array}{l}\text { Educational Technology Research and } \\
\text { Development, 2012-2017 }\end{array}$ & $\begin{array}{l}\text { Journal of Scholarship of Teaching and } \\
\text { Learning, 2012-2016 }\end{array}$ \\
\hline Educause Review, 2012-2017 (Issue 1) & Management Learning, 2012-2017 (Issue 1) \\
\hline $\begin{array}{l}\text { European Journal of Open Distance and } \\
\text { e-Learning (EURODL), 2012-2016 }\end{array}$ & $\begin{array}{l}\text { Management Teaching Review, } 2016 \text { (year of } \\
\text { inception) }\end{array}$ \\
\hline $\begin{array}{l}\text { Higher Education: The International } \\
\text { Journal of Higher Education and }\end{array}$ & $\begin{array}{l}\text { (Merlot) Journal of Online Teaching and } \\
\text { Learning (JOLT), 2012-2015 }\end{array}$ \\
\hline Educational Planning, 2014-2017 (Issue 1) & Nursing Education Perspectives, 2012-2016 \\
\hline Higher Education Research and & Online Journal of Distance Learning \\
\hline Development, 2012-2017 & Administration, 2012-2016 \\
\hline Instructional Science, 2012-2016 & Online Journal of Nursing Informatics, 2012- \\
\hline International Journal of E-Learning and & 2016 \\
\hline $\begin{array}{l}\text { Distance Education (previously the Journal } \\
\text { of Distance Education), 2012-2016 }\end{array}$ & $\begin{array}{l}\text { Open Learning: The Journal of Open, Distance } \\
\text { and e-Learning }(O L), 2012-2017 \text { (Issue 1) }\end{array}$ \\
\hline $\begin{array}{l}\text { International Journal on E-Learning, 2013- } \\
2016\end{array}$ & $\begin{array}{l}\text { Online Learning: The Official Journal of the } \\
\text { Online Learning Consortium (previously The }\end{array}$ \\
\hline $\begin{array}{l}\text { International Journal of Nursing Education } \\
\text { Scholarship, 2012-2016 }\end{array}$ & $\begin{array}{l}\text { Journal of Asynchronous Learning Networks), } \\
\text { 2007-2017 (Issue 1) }\end{array}$ \\
\hline $\begin{array}{l}\text { International Journal of Teaching and } \\
\text { Learning in Higher Education, 2013-2016 }\end{array}$ & $\begin{array}{l}\text { Quality Assurance in Education, 2012-2017 } \\
\text { (Issue 2) }\end{array}$ \\
\hline $\begin{array}{l}\text { International Review of Research in Open } \\
\text { and Distributed Learning, 2012-2016 }\end{array}$ & $\begin{array}{l}\text { Quarterly Review of Distance Education, } \\
\text { 2012-2016 (Issue 3) }\end{array}$ \\
\hline Internet and Higher Education, Sept. 2011- & Review of Educational Research, 2012-2016 \\
\hline 2017 (Issue 1) & Research in Higher Education, 2012-2017 \\
\hline Journal of Computer Assisted Learning, & (Issue 2) \\
\hline 2012-2017 (Issue 1) & Studies in Higher Education, 2012-2017 (Issue \\
\hline Journal of Computer and Education & 4) \\
\hline Research, 2013-2017 & $\begin{array}{l}\text { Teaching in Higher Education, 2013-2017 } \\
\text { (Issue 2) }\end{array}$ \\
\hline
\end{tabular}


With a focus on online class size, the authors systematically examined the table of contents for each issue of 43 journals over the five-year period, reviewing titles and abstracts, and identifying studies about class size associated with the factors of student learning processes/learning outcomes and various pedagogical approaches (e.g., learning communities, Bloom's taxonomy, deep learning, collaborative learning, MOOCs, objectivism-constructivism, the CoI model). They also reviewed articles on faculty workload as they pertained to class size and pedagogical intent. In addition to articles published from 2012-2017, the authors reviewed and included single articles of varying dates that had been prominent in selected articles' reference lists, had serendipitously come to their attention, or were located through keyword searches (a limited number). Most, but not all, were peer-reviewed; those not peer-reviewed contained content from well-recognized institutional sources (e.g., Morse, Brooks, \& Mason, 2018, U.S. News and World Report College Rankings).

The vast majority of articles used in this review addressed online courses, but eight were included that contained relevant findings for hybrid and face-to-face courses. The studies crossed disciplines and undergraduate, graduate, and doctoral program education levels.

For the 58 studies identified as relevant for inclusion, we retrieved full texts of the pertinent articles, qualitatively annotated each, and subsequently used inductive reasoning methods to thematically analyze the content (see study summaries presented in Table 1).

\section{Results}

A summary of the compiled evidence-our thematic findings from the 58 articles connecting online class size to learning goals and pedagogical practices, student learning outcomes, and faculty workload-is displayed in Table 4. The more than six-year review period revealed a maturation in the body of knowledge regarding learning factors associated with differing class sizes. But, as the researchers found in the 2011 work, no consistent cross-study guidelines have appeared in the research literature, now extending up through 2017, to guide university class size decisions aligned with pedagogy.

Our synthesis of research on specific student numbers recommended for online courses follows. When sizes were discussed, most of the reviewed articles identified classes of "small," "medium," or "large" without specifying what numbers were associated with each term (Chen et al., 2017). We discuss why guidelines are needed to align enrollment with pedagogy and propose a framework to guide decisions on class sizes with a breakdown of recommended enrollment numbers, in the Discussion.

\section{When Are Small Classes Needed?}

We found extensive evidence supporting the use of smaller online classes for learning subject to the following four types of educational intent (see Table 4):

a. nuanced learning dependent on substantive online interaction (30 articles),

b. student development (22 articles),

c. mastery of complex phenomena (16 articles), and

d. development of higher order thinking (14 articles).

With less robust research support than for the four preceding purposes, the literature identified three additional conditions that call for smaller classes: 
e. inspiring and challenging students (six articles),

f. meeting learning needs under conditions of high student diversity (five articles), and

g. specialization learning - for example, developing skills in writing, language, and clinical competencies (three articles).

While a preponderance of evidence justifying small classes characterizes the first four educational purposes $(\mathrm{a}-\mathrm{d})$, all seven $(\mathrm{a}-\mathrm{g})$ reflect credible and consonant reasoning. In the following paragraphs, we provide descriptions of the studies' thematic content; Table 4 complements this section by providing elaboration, examples, and author citations.

Table 4

Research Evidence of Learning Goals and Pedagogical Strategies Requiring Smaller Classes

\section{Descriptions of Learning Goals and Pedagogies} Requiring Smaller Classes

(a) Creating a learning community through substantive interaction:

meaningful and nuanced learning dependent on collaborative relationships and interaction; includes diverse perspectives for the social construction of reality; interaction about course material and course-related ideas; enables social presence; student engagement; positive student attitudes about the discipline; faculty input on future career direction. Occurs between faculty and students and among students.

\section{Authors}

Batts, 2008; Beattie \& Thiele, 2016; Benton \& Pallett, 2013; Colwell \& Jenks, 2004; Goldman, 2012; Haynie, 2014; Hewitt \& Brett, 2007; Holzweiss et al., 2014; Horning, 2007; Jaggars \& $\mathrm{Xu}$, 2016; Jahang et al., 2010; Jones, 2015; Kim, 2013; Kingma \& Keefe, 2006; Lai, 2015; Lee et al., 2011; Maringe \& Sing, 2014; Palmer \& Smith, 2013; Parks-Stamm et al., 2016; Qiu et al., 2012; Ravenna, 2012; Russell, 2015; Russell \& Curtis, 2013; Shaw, 2013; Sorensen, 2014, 2015; Taft et al., 2011; Tynan et al., 2015; Udermann, 2015; Walls, 2016

Example of interactive pedagogy: Student learning about how to do research is heavily dependent on interaction. Students arrive at the challenge of conducting research by first acquiring foundational knowledge about types of research, research methods, data collection, statistical and qualitative data analysis, and drawing inferences from results. Once students master knowledge of fundamental areas of the research process, they are ready to apply it by considering the various ways to study the phenomena of interest. Through online intragroup interactions, students may generate research questions or hypotheses and set about the task of debating different research approaches, examining the pros and cons of each option. Faculty direction to students would flow from immersion in the students' discussion, an understanding of key choice points in research design and their benefits and limitations (i.e., investments of time and costs and considerations of differing perspectives of external stakeholders), and the feasibility of potential approaches. Interactive pedagogy drawing on faculty expertise assumes constructivist and developmentally oriented characteristics.

(b) Developing students:

faculty providing incremental student feedback, mentoring; may involve creativity, problemsolving, research, writing, communication, and other skills; students access faculty expertise; faculty use the CoI practice of teaching presence
Artemiou et al., 2013; Benton \& Pallett, 2013; Curriculum Committee, 2012; Holzweiss et al., 2014; Horning, 2007; Jahang et al., 2010; Jaggars \& Xu, 2016; Jones, 2015; Lai, 2015; Maringe \& Sing, 2014; Mbati \& Minnaar, 2015; Monks \& 2012; Russell, 2015; Russell \& Curtis, 2013; Salley \& Shaw, 2015; Schwartz, 2014; Sorensen, 2014, 2015; Taft et al., 2011; Walls, 2016 


\section{Descriptions of Learning Goals and Pedagogies} Requiring Smaller Classes

\section{Authors}

Bristol \& Kyarsgaard, 2012; Colwell \& Jenks, 2004; Curriculum Committee, 2012; Holzweiss et

(c) Mastering complex phenomena: critical thinking; deep learning with constructivist pedagogy

(d) Attaining higher order learning:

advanced content at the application level or above on Bloom's taxonomy

(e) Effects of instructor inspiration:

more challenge for and effort by students; greater motivation and enthusiasm; better study/work habits; greater student average progress on course objectives

Re: instructor inspiration: Sorensen $(2014,2015)$ reported that faculty with smaller enrollments created stronger intracourse relationships and more fully shared their knowledge and expertise about the subject matter, thereby enabling the expression of teacher and student social presences and engagement, than did faculty in larger classes. Meaningful relationships generate emotions that facilitate learning (Berg \& Seeber, 2016). In Monks and Schmidt's (2011) natural experiment of 1,928 course sections, smaller classes were found to correlate with greater faculty enthusiasm for teaching the class, effectiveness of teaching methods, clarity of presentations, stimulation of interest, daily preparedness, and adequacy of graded material relative to course content. Not significant but trending in the same positive direction were increased critical thinking, availability of the instructor, perceived respect the instructor had for students, and timeliness of feedback. Complementing these findings, Holzweiss et al. (2014) found that when students did not believe the faculty were fully engaged in a course, their perception of academic quality diminished. Palmer \& Smith (2013) noted that the personal attention and feedback that a teacher can give in smaller classes, which they identified as the "teacherly" aspects of learning, are inspirational.

(f) High student diversity:

lower income, first-generation in college, low

SAT scoring or grades, Black or Latino, or

international students

(g) Specialization courses; writing-intensive basic Betts, 2008; Jones, 2015; Russell \& Curtis, 2013

English, language learning, and clinical skills

Beattie \& Thiele, 2016; Bettinger \& Loeb, 2017;

De Giorgi et al., 2012; Diette \& Raghav, 2015;

Maringe \& Sing, 2014

courses 
Studies supporting small classes for learning dependent on substantive interaction (a) emphasized that the multiple perspectives of student peers and the expert knowledge of faculty, accessed through interaction, enriches online learning. While factual information provides the underlying structure for any knowledge, at advanced levels of learning additional demands arise: reasoning through multivariate or ill-structured problems, considering different perspectives of a problem (Hew \& Cheung, 2011), or selecting approaches attuned to contextual factors and political influences. Factors such as these must be identified, weighed, and negotiated to identify a preferred action or set of actions. And once an action is chosen, learners confront the need to adjust approaches as new understandings emerge.

Social presence of faculty and students, as defined in the CoI model and identified as requiring small classes, is richly developed in high-quality interactive learning courses, as are teaching and cognitive presences. In any course, faculty develop the content, structure, and evaluation components for learning, set expectations and goals, and design learning activities. In interactive learning, instructors add actions such as facilitating focused and substantive discourse, correcting students' misconceptions, identifying areas of consensus and disagreement, providing developmental feedback, and building knowledge understanding among student participants. In CoI interactions, course relationships are multidimensional and, ideally, both faculty and students tend to demonstrate authenticity and engagement (Orcutt \& Dringus, 2017).

A learning pedagogy high in interaction is responsive to both individual and group learning and is teaching intensive. The faculty workload associated with frequent knowledge-building interactions, regular interventions, and student assessments is impractical in large classes.

Research on developing students (b) called for equally time-intensive teaching strategies. College courses on language learning, public speaking, English writing, clinical skills, or specialization (g) are examples appropriate for developmental learning strategies. Given the variation in knowledge and skill levels among students, faculty performance feedback is provided to students through time-intensive assessments of individual assignments, demonstrations, or videos of clinical skills practice. Developmental pedagogies commonly employ research and writing, problem-solving, creative activities, practice, role-playing, and projects through which students demonstrate, incrementally, their learning accomplishments. While the grades attached to an assignment are often a primary motivator for student achievement, in courses that are oriented to student development, faculty routinely engage in informal coaching. Coaching enables faculty expertise to be shared in a variety of "soft" ways that don't carry the force of a grade designation. It elicits an emotional connection between faculty and student that feels more collegial than does the "judgment" impact of a grade. Students understand intuitively the difference between "being graded" and "being coached," the latter being a more emotionally fulfilling and motivating experience.

Courses with a core purpose of student development depend heavily on the teaching, cognitive, and social presence practices of the CoI model. Faculty work is close-up and individually focused; students are assessed for their cognitive presence or skill growth within the learning environment. In developmentally focused courses with a sense of community, students often share an awareness of their peers' developmental strengths and weaknesses. Faculty work of assessing and coaching students while creating a safe and supportive learning environment is dependent on smaller and more intimate courses, which tend to engender trust. 
Studies recommending small classes for learning about complex phenomena (c) and at higher levels of Bloom's taxonomy (d) identified faculty's expert leadership of interactive discussions, provision of individual and group feedback, and coaching for critical thinking. Garrison (2012) and Kasi and Yorks (2016) concluded that research on critical thinking and deep understanding indicates that this level of learning is hard to achieve without discourse. In most subject areas, it is difficult to imagine how students could advance higher order or complex thinking without faculty use of constructivist pedagogy, which takes contexts into consideration and moves students beyond orderly factual information into conceptions of multifactorial or ambiguous areas.

Developing complex and higher order thinking in students (c) requires faculty to design and facilitate applied learning activities while monitoring individual knowledge gains in analysis, synthesis, evaluation, and/or creation. Providing developmental formative and summative feedback to students is teaching intensive; therefore, educational efficacy is dependent on manageably small courses.

Studies identifying small classes as consistent with inspiring and challenging students (e) indicate such courses create the right conditions for greater student connection to the professor, thereby heightening student engagement with the teacher and the course material. Assignments in inspiring milieux tend to offer more academic challenge to students while also being more timeconsuming for faculty to grade.

Studies recommending small classes for learning under conditions of high student diversity (f) offered relatively self-explanatory rationales: Because of differentials in backgrounds, prior knowledge, interpersonal, and language and writing skills, students from diverse, underserved, and/or minority backgrounds need more individualized faculty attention to succeed (Walls, 2016).

Additional benefits associated with smaller classes, such as the following, appeared in a lesser number of reviewed studies (see Table 5, a supplement to Table 4, for references on the additional benefits):

- positive student evaluations of instructors and satisfaction with courses;

- higher perceived student learning and better student learning performance;

- sense of group cohesion and connectedness;

- faculty involvement that encourages student participation; and

- positive effects associated with faculty workload (e.g., time spent interacting, providing feedback, assessing/evaluating student work), accessibility and responsiveness to students, and student evaluations of instructors.

In large classes, negative but nonsignificant relationships were found for critical thinking, availability of the instructor, perceived respect the instructor had for students, and provision of feedback (Ravenna, 2012; Russell \& Curtis, 2013; Sorensen 2014, 2015). 
Table 5

Supplement to Table 4: Research Sources Indicating Additional but Research-Limited Benefits Associated With Smaller Classes

Additional Benefits Associated With Smaller Classes

Sources

Refs.

Bedard \& Kuhn, 2008; Benton \& Pallett, 2013;

Student positive evaluations of instructors and satisfaction with courses Chapman \& Ludlow, 2010; Cheng, 2011; Kingma \& Keefe, 2006; Lee et al., 2011; Mandel \& Sussmuth, 2011; Monks \& Schmidt, 2011; Palmer \& Smith, 2013; Russell \& Curtis, 2013; Sapelli \& Illanes, 2016; Shaw, 2013; Udermann, 2015; Walls, 2016

Better student learning and performance

De Giorgi et al., 2012; Diette \& Raghav, 2015; Horning, 2007; Johnson, 2010; Maringe \& Sing, 2014; Monks \& Schmidt, 2011; Salley \& Shaw, 2015; Shaw, 2013; Walls, 2016

Higher perceived student learning

Chapman \& Ludlow, 2010

Positive effects on faculty associated with workload (e.g., sufficient time to interact, provide feedback, assess/ evaluate student work); responsiveness to students; and Chapman \& Ludlow, 2010; Curriculum Committee, 2012; Freeman, 2015; Goldman, 2012; Tynan et al., 5 2015 higher student evaluations of instructors Sense of group cohesion and connectedness, and faculty participation that encouraged student participation

Colwell \& Jenks, 2004; Haynie, 2014; Monks \& Schmidt, 2011

In summary, the research reviewed for this study consistently linked smaller online classes to student development; student engagement with challenging material; higher order thinking; deeper levels of personal interactions, participation levels, and connectedness; socially constructed understandings; individualized faculty feedback; writing and creative assignments; full access to faculty expertise; and positive student reviews of faculty. Small courses enable teaching methods that differ markedly from those feasible with large enrollments. Large classes inherently drive pedagogy away from the above practices toward strategies that effectively disseminate factual information and require less individualized faculty-student interaction (Chapman \& Ludlow, 2010; Mandel \& Sussmuth, 2011).

\section{When Are Large Classes Appropriate?}

The case for large classes in higher education is reasonable and legitimate, justified primarily on economic grounds (Maringe \& Sing, 2014). Since universities must generate budgetenhancing revenues to survive, and salaries are the single largest operational expense, small classes cannot realistically prevail uniformly across college courses. Larger classes produce financial surpluses via scale while smaller classes for advanced learning consume more resources. An 
intentional mix of large and small classes can balance revenues and expenses by using the large courses to cross-subsidize those requiring smaller enrollments.

Evidence from our research review justifying large enrollments in online courses aligned with pedagogies for foundational and factual learning - that is, those requiring relatively low levels of critical thinking; limited personalized interaction with faculty, little individualized instruction, formative feedback, sense of community, or shared knowledge creation; and less higher order thinking, intellectual challenge, skill development, problem-solving, research and writing, journal reflection, or faculty-moderated discussions (E1 Tantawi et al., 2015; Haynie, 2014; Holzweiss et al., 2014; Mandel \& Sussmuth, 2011; Maringe \& Sing, 2014; Ravenna, 2012; Rees, 2017; Taft et al., 2011). Foundation-level learning can rely on lecture- and testing-centered pedagogies that emphasize content recall and demonstration of knowledge at the lower levels of Bloom's taxonomy (Pelech et al., 2013). Many college courses involve basic levels of learning that can be managed in large classes.

Schwartz (2014) examined what learning means in online environments from the perspective of the cognitive and learning sciences. Using Khan Academy (KA), a purveyor of online content, as an example of what he called "the illusion of understanding," Schwartz identified didactic education with testing, as practiced by KA, as inadequate to the task of building complex understandings in students. Among other characteristics, complex understanding is described as learning dependent upon experiences that provide formative feedback, sensitize students to context, require experimentation and practice, and lead to building models of hierarchically organized knowledge (i.e., conditions identified for small classes). MOOCs, selfstudy, and independent learning courses share pedagogical characteristics with those of KA. However, other researchers note that basic levels of factual knowledge acquired under conditions of didactic education - in large classes - can succeed in providing the foundation for subsequent development of more complex understandings (Fischer, 2014; Picciano, 2017; Rees, 2017).

Some studies described the differences between undergraduate and graduate courses and how pedagogies need to differ based on student learning level. Holzweiss et al. (2014) identified constructivist teaching methods and CoI practices as most suitable for graduate students learning at middle to upper levels of Bloom's taxonomy. Graduate students are focused on advanced content and skill development for specific professional fields. Their education requires an understanding of and appreciation for the flexible and growing nature of knowledge, taught by expert faculty who support and encourage them as novice members of the academic disciplinary community. In contrast, undergraduate students in lower division and some upper division courses, and graduate students in factual information courses, learn foundational knowledge efficiently and effectively in classes with large enrollments.

With advances in computer technology, some subject areas can accommodate large classes by supporting substantial individualized student learning outside of formal classes. Math and information sciences courses that supplement class time with labs and computerized tutorials incur costs in initial setup and design but save personnel costs significantly over time (Gleason, 2012). Advances in computerized practice and tutorial labs extend to the sciences. Graduate students and tutors can staff labs and coach students in an informal lab setting via hands-on learning while enabling very large courses for faculty lectures. Such settings that individualize instruction to a learner's specific needs have proven effective, whereas nonindividualized or independent online learning generally have not (Means et al., 2010). 


\section{What Number of Students Constitutes a Small, Medium, or Large Class?}

We found an abundance of articles about online pedagogies. As detailed in Table 1, those selected for this analysis addressed the class-size implications associated with educational intent and pedagogical strategy. Only 18 of the 58 selected articles went beyond basic small/medium/large language to specify numbers of students for each size category. Those research recommendations are displayed in Table 6, Recommendations Specifying Enrollment Numbers in Smaller, Medium, or Larger Classes.

Table 6

Research Recommendations Specifying Enrollment Numbers in Smaller, Medium, or Larger Classes $(n=18)$

\section{Authors and Dates}

The Academic Senate for California Community Colleges, Curriculum

Committee, 2012

Benton \& Pallett, 2013 Betts, 2008

Colwell \& Jenks, 2004

Goldman, 2012

Haynie, 2014

Hewitt \& Brett, 2007

Horning, 2007

Jones, 2015

Kingma \& Keefe, 2006

Lai, 2015

Mandel \& Sussmuth,

2011

Morse, Brooks, \& Mason (2018), U.S. News and

World Report College

Rankings, 2019

Parks-Stamm, Zafonte, \&

Palenque, 2016

Qiu, Hewitt, \& Brett,

2012

Sorensen, 2014, 2015

Taft et al., 2011

\section{Recommendations}

College English classes: 20 students; 15 students for basic skills courses. In mathematics courses, a ratio of 30 students for one teacher. Delineates pedagogies requiring teaching intensity.

Small: $10-14$; medium: $15-34$; large: $35-49$; and very large: $50+$. No more than 20-25 students in online graduate courses; less than 20 students in specialization courses.

Maximum undergraduate course size: 20 students; $8-15$ students for graduate courses.

Optimal online MBA class size (with discussion): 12 students. Online synchronous courses of no more than 15 students.

Ideal enrollment of 8-30 students, depending on the type of course. No more than 20 students in any English writing class; ideally, should be limited to 15 (smaller for remedial sections).

Online master's courses of 25-35 students. Smaller classes for practice skills courses and advanced clinical skills courses.

Courses of $15-25$ students.

Online doctoral course: 12 students.

Maximum size of 19 students.

Awards full points for undergraduate classes with $\leq 20$ students.

Small classes less than 15 students; medium classes 15-30 students. Optimal class size $13-15$ students.

Small: classes with 10 students or less; medium: classes with 11-19 students; large: classes with 20-30 students.

Small: $\leq 15$ students

Medium: 16-30 students

Large: $\geq 30-$ no known upper limit of students 
Of the 18 articles, just four proposed actual student numbers associated with a small, medium, or large category. There was virtually no agreement on what constituted large classes; proposed numbers ranged from 20 students to "no known upper limit" (three articles). For medium sizes, four articles recommended 11-30 students. There was convergence among four articles that small classes should hold $\leq 15$ students.

Regarding differences between undergraduate and graduate courses, the recommended range for undergraduate courses was 15-30 students, with more refined specifications for basic skills $(\leq 15)$ and mathematics courses (30). Size recommendations for masters/graduate courses ranged from eight to 35, a large spread; one author called for $<20$ for specialization courses. Doctoral courses were mentioned in just one study, with a recommendation of eight students. The remaining sources did not differentiate class sizes between undergraduate and graduate courses, recommending eight to 50 or more online students, with lower and upper limits varying widely among the studies.

In conclusion, this literature review identified substantial research attention linking pedagogical practices to online course sizes, but it offered ambiguous guidance on specific student enrollment numbers associated with student learning and faculty pedagogies. Below, we discuss and present our conclusions from the findings, our recommendations for course sizes, and a framework for class enrollment decisions.

\section{Discussion and Conclusions}

Class enrollment numbers in higher education settings are influential factors impacting online student learning, faculty pedagogy, school finances, and faculty workload, yet they have been addressed without sufficient specificity or consensus using learning theory to provide policy guidance. This research was intended to advance the knowledge and practice of evidence-based class size determinations in higher education, a factor repeatedly linked to student learning in online courses. The authors presented evidence from a comprehensive literature review of 43 cross-disciplinary education journals on student learning and the implications of various pedagogical practices for class sizes. Fifty-eight selected articles were inductively analyzed and informed the findings for the study.

Our findings demonstrate clear and continuing academic interest in online course sizes as they align - or fail to align-with research about student learning. We found substantial research support for structuring course enrollments consistent with educational goals and pedagogical strategies known to address student learning needs effectively. The reality that student learning needs and pedagogical practices vary meaningfully — by student educational level, demographics, complexity of subject matter, faculty teaching methods, and university policies-has historically confounded the identification of "the right number" for course enrollments. Student competencies, learning expectations, and pedagogical variations bring complexity to calculations of class sizes and faculty workloads. Wide and random size discrepancies are reported across studies, universities, between departments within a single setting, and between face-to-face and online courses (Mupinga \& Maughan, 2008). Research clearly indicates that in the world of online education, no one size fits all courses. In spite of a continuing interest in online class sizes, there is a striking absence of coherent guidelines on student enrollments. 
University policies on class sizes and academic staff workload are frequently guided more by historical precedents, "what other colleges do," or by untested assumptions about reducing costs or scaling up revenues than by research-based measures of learning and staffing effectiveness. Often, courses have student numbers arbitrarily assigned based on their placement within a curriculum. Additionally, online courses are generally acknowledged to be more teaching intensive than are face-to-face courses due to extra tasks associated with them, increased faculty preparation and interaction time, technical complexity, contextual variability, and student supports needed. The multiplicity of relevant factors has muddied the development of guidelines for online course sizes and faculty workload expectations (Tynan et al., 2015).

Most university workload assignment practices fail to take into consideration the educational intent and pedagogical strategies faculty apply in their courses, how variable or appropriate they are, or how effectively they educate students in the near and long-terms. Colleges tend to apply standard formulae: for example, tenured professor $\mathrm{X}$ is given a semester workload of three 3-credit-hour graduate courses with a course cap of 25, while part-time faculty member $Y$ has a workload of five 3-credit-hour undergraduate courses with a course cap of 40 students. Standardized workload assignments are efficient to implement and, because they are commonly used, may on the surface appear to be reasonable assignments. However, other than differentiating undergraduate from graduate students and tenure track from non-tenure-track faculty, these workload examples take no account of expected student learning goals or faculty pedagogical methods appropriate to a course. While student enrollment numbers intentionally matched to course-appropriate pedagogy should be at the center of workload calculations, instead routine application of pre-established enrollments leaves the door open for disparities in the quality of student learning and inequities across faculty workloads. The authors found no evidence, explicit or implicit, of university online workload assignments that considered how student learning needs were aligned with pedagogical methods and course enrollment sizes (Fischer, 2014; Pelech et al., 2013).

Online course sizes should advance student education without compromising institutional fiscal stability. It is fair to conclude that universities need an evidence-based analytical framework for assisting faculty and administrators to make differentiated enrollment size decisions that take into account student learning goals, pedagogical methods, university financial needs, and faculty workload. Our results suggest three conclusions of interest bearing on enrollment decisions in online courses.

\section{Established Educational Theories Offer Guidance for Online Class Size Decisions}

To structure our findings regarding how well different class sizes function in the distancelearning world, we followed earlier class size researchers (Taft et al., 2011) in applying three recognized educational theories: objectivist-constructivist pedagogies, Bloom's taxonomy, and the CoI model. Each theory invokes a continuum for a range of teaching practices that address, for example, the level of learning, complexity of subject matter, and degree of faculty engagement required for effective student learning. When the three theories are used to examine the implications for online class sizes, they show considerable pedagogical overlap, yet each theory adds a singular perspective for categorizing courses as high, medium, or low in pedagogical demand.

Given the reality that college courses require no automatic pedagogical approach - neither constructivism nor objectivism is mandated for any given course, Bloom's taxonomy allows for 
variation across targeted learning levels, and choices must be made for degree of implementation of the CoI model — only a course-specific analysis should guide enrollment sizes.

\section{Use of an Analytical Framework for Online Course Enrollment Numbers Is Timely and Necessary}

We identified a clear need for ways to structure university decisions on class sizes in online courses. This final section addresses the need explicitly. We propose a stabilization of class size terminology, followed by a framework that employs the stabilized terminology and incorporates pedagogical factors in enrollment decisions.

To support university financial stability, our framework advances the use of larger classes for courses primarily focused on foundational and/or factual knowledge acquisition. Research reviewed for this study provided no evidence that student learning was disadvantaged when the pedagogical characteristics for large classes described in the Findings section were applied. Universities are fiscally responsible in assigning large enrollment sizes to courses fitting these criteria: large classes satisfy foundational learning needs while generating budgetary surpluses, some of which can be used to cross-subsidize courses requiring smaller student-to-faculty ratios. Concurrently, existing research promotes smaller class sizes under conditions specified earlier: learning associated with higher order and critical thinking, reasoning through complexity, incorporation of context and a diversity of perspectives, creative problem-solving, and developing individual students in research, writing, and disciplinary expertise.

Pedagogical requisites for learning should drive the choice of online class sizes. Given the connection of learning goals and pedagogical strategy to class size, and the limited evidence of specific online student enrollment numbers, researchers need to build a consensus on the number of students associated with each class size. Researchers have prescribed different class sizes generally characterized as small, medium, or large. This terminology is a good starting point, but we determined that adding specific numbers and intermediate terms to cover the ground between small and medium and between medium and large provides a more refined and actionable fivecategory spread. Our findings synthesized data from the research reviews to create five categories with specific student numbers. Below, we propose online course sizes compatible with both financial considerations and the educational theories applied in this study.

The evidence compiled on student enrollment numbers, displayed in Table 6, and the identified pedagogical characteristics associated with small, medium, and large classes, enabled us to propose specific student enrollment numbers for online college class sizes. We recommend that the following terminology be adopted:

\section{Online Class Size Number of Students}

$\begin{array}{ll}\text { Small: } & \leq 15 \\ \text { Small-medium: } & 16-23 \\ \text { Medium: } & 24-30 \\ \text { Medium-large: } & 31-39 \\ \text { Large: } & 40-\text { no upper limit }\end{array}$


One Size Does Not Fit All: Toward an Evidence-Based Framework

for Determining Online Course Enrollment Sizes in Higher Education

We apply this terminology in an enrollment size framework structured according to pedagogical strategies in Table 7. The goal for class size decisions should be to balance learning goals and university revenue needs by applying a model that respects both.

\section{Table 7}

Recommended Student Enrollment Sizes by Learning Needs and Pedagogical Strategies, With Course Examples

\section{Class Size}

Small:

$\leq 15$ students

Small-medium:

16-23 students

Medium:

24-30 students

\section{Learning Needs and Pedagogical Strategies}

- Faculty instruction, extensive class discussion; individual projects and papers, one major; in-depth research on course topics of interest

- Constructivist methods

- Application level and above of Bloom's taxonomy

- CoI:

$\circ$ teaching presence includes course design and organization, facilitating discourse, and direct instruction; individualized feedback

$\bigcirc$ extensive student cognitive presence

- well-developed faculty and student social presence

- Faculty instruction, class discussion; student debates; student public-speaking practice; writing and/or math assignments; written application/analysis assignments; group project work; written term paper

- Mix of objectivist and constructivist methods

- Application and analysis levels of Bloom's taxonomy

- CoI:

$\circ$ teaching presence includes course design and organization, facilitating discourse, and direct instruction; individualized feedback

- student cognitive presence in class and on performance assignments

- faculty and student social presence exhibited

- Mix of faculty lecture, class discussion, small-group project work; quizzes and/or tests, short essays

- Predominantly objectivist method, some constructivism

- Knowledge, comprehension, and application levels of Bloom's taxonomy

- CoI:

$\circ$ teaching presence includes course design and organization, facilitating discourse, direct instruction; feedback to student group as a whole, some individualized feedback

- moderate level of student cognitive presence

- moderate level of faculty and student social presence

\section{Course Examples}

Undergraduate level: information technology research; interventions for children with moderate to severe disabilities; writing for publication

Graduate level: research design and methodology; advanced interventions in psychology practice

Undergraduate level: ESL writing; creative writing; anthropology of gender and sexuality; debate; public speaking; composition; public relations; mathematical modelling; advanced comparative religions; online journalism

Graduate: case studies in language translation; research statistics

Undergraduate level: ethics; quantitative data analysis; race and ethnicity; cultural evolution

Graduate: public finance; communication disorders of the aged; computer applications in business; infectious diseases in the developing world 
One Size Does Not Fit All: Toward an Evidence-Based Framework

for Determining Online Course Enrollment Sizes in Higher Education

\section{Class Size}

Medium-large:

31-39 students

Large:

40-no known upper limit of students

\section{Learning Needs and Pedagogical Strategies}

- Predominantly faculty lecture with selected periods of class discussion; students assessed by testing, quizzes, short-answer questions, automated activities

- Mainly objectivist method

- Knowledge and comprehension levels of Bloom's taxonomy

- CoI:

$\bigcirc$ teaching presence includes course design and organization, facilitating discourse; feedback to student group as a whole

- cognitive presence limited to test or quiz performance and brief interactions

- faculty and student social presence limited to episodic discussions

- Predominantly faculty lecture; students assessed by standardized testing of knowledge

- Objectivist method

- Knowledge and comprehension levels of Bloom's taxonomy

- CoI:

- teaching presence limited to course design and organization, evaluation

- cognitive presence limited to test performance

- minimal faculty and student social presence

\section{Course Examples}

Undergraduate: principles of economics; introduction to sociology; history of science; health disparities in the U.S.; computer science with individualized lab tutoring

Graduate: pharmacology; sports governance

Undergraduate level: world history; introduction to biology; global archeology; world religions; history of mathematics

Graduate: neuroanatomy; adult pathophysiology

Table 7 details recommended student enrollment sizes (column 1) for specified learning needs and pedagogical strategies (column 2), and provides illustrative course examples for each category (column 3). We selected course examples from our own universities whose learning strategies we deduced to correlate with student learning level, complexity of subject matter, interaction requirements, and student diversity. These attributes may or may not align with how courses are taught in other university settings and are not intended to be prescriptive. Instead, we propose that our recommendations lead to local academic discussions about structuring class sizes to integrate pedagogical factors into decision-making.

Our proposed framework rests on the best evidence compiled from articles found in recent higher education journals reported by researchers from a variety of disciplines. We do not view the question, What is the right number of students to enroll in online college courses? as definitively answered by our work, but we do believe that we have put forward a model with high generalizability worthy of testing across university settings. We encourage future research examining the educational and financial issues addressed by this review as well as studies reporting on decision-making processes and results from implementing similar proposed frameworks.

Our guidelines for class sizes in online courses are recommended for trial and evaluation at varying levels and across different disciplines in universities. We urge universities to draw on the combined expertise of both administrative leaders and experienced faculty who, together, deliberate to determine course enrollments. The process and methods for such decision-making need further development. We have begun trialing one rubric, displayed in Table 8 (Implementation Rubric for Experimentation With Class Size Decisions), with some success among university faculty; it may be a useful beginning model for experimenting with application/implementation methods for our class size recommendations. 
One Size Does Not Fit All: Toward an Evidence-Based Framework

for Determining Online Course Enrollment Sizes in Higher Education

\section{Table 8}

\section{Implementation Rubric for Experimentation With Class Size Decisions}

Name of online course:

Level of course:

UG lower division

UG upper division

Master's

$\mathrm{PhD}$

Other:

How you would rate this course on each of the pedagogical theories? Circle the column cell most closely describing each of the 3 teaching methods; if the course falls between two rows, circle both.

\begin{tabular}{|c|c|c|c|}
\hline $\begin{array}{l}\text { Pedagogical } \\
\text { Level \& Theory: } \\
\text { Point Allocation }\end{array}$ & $\begin{array}{l}\text { Bloom’s Taxonomy } \\
\text { (Column A) }\end{array}$ & $\begin{array}{l}\text { Objectivist-Constructivist } \\
\text { (Column B) }\end{array}$ & $\begin{array}{l}\text { Community of Inquiry } \\
\text { (Column C })\end{array}$ \\
\hline $1 \mathrm{pt}$. & $\begin{array}{l}\text { Knowledge and } \\
\text { comprehension levels of } \\
\text { taxonomy }\end{array}$ & $\begin{array}{l}\text { Predominantly faculty lecture; } \\
\text { students assessed by standardized } \\
\text { testing of knowledge. }\end{array}$ & $\begin{array}{l}\text { Teaching presence limited to course design and } \\
\text { organization, delivery, student evaluations. } \\
\text { Cognitive presence limited to test performance. } \\
\text { Minimal faculty and student social presences. }\end{array}$ \\
\hline 2 pts. & $\begin{array}{l}\text { Knowledge and } \\
\text { comprehension levels of } \\
\text { taxonomy }\end{array}$ & $\begin{array}{l}\text { Predominantly faculty lecture with } \\
\text { selected periods of class discussion; } \\
\text { students assessed by testing, quizzes, } \\
\text { short answer questions, automated } \\
\text { activities. }\end{array}$ & $\begin{array}{l}\text { Teaching presence includes course design and } \\
\text { organization, delivery, some discourse } \\
\text { facilitation. Feedback largely to student group as } \\
\text { a whole. } \\
\text { Cognitive presence limited to students' test or } \\
\text { quiz performance and brief interactions. } \\
\text { Faculty and student social presences limited to } \\
\text { episodic interactions. }\end{array}$ \\
\hline 3 pts. & $\begin{array}{l}\text { Knowledge, } \\
\text { comprehension, and some } \\
\text { application levels of } \\
\text { taxonomy }\end{array}$ & $\begin{array}{l}\text { Mix of faculty lecture, class } \\
\text { discussion, small group project work; } \\
\text { quizzes and/or tests, short } \\
\text { papers/essays. }\end{array}$ & $\begin{array}{l}\text { Teaching presence includes course design and } \\
\text { organization, delivery, facilitating discourse, } \\
\text { direct instruction. Feedback to student group as a } \\
\text { whole, some individual feedback. } \\
\text { Moderate level of student cognitive presence. } \\
\text { Moderate level of faculty and student social } \\
\text { presences. }\end{array}$ \\
\hline 4 pts. & $\begin{array}{l}\text { Application and analysis } \\
\text { levels of taxonomy. } \\
\text { Requires critical thinking, } \\
\text { ability to think } \\
\text { holistically, use different } \\
\text { perspectives. }\end{array}$ & $\begin{array}{l}\text { Faculty instruction, class discussion; } \\
\text { student debates; student public } \\
\text { speaking practice; writing and/or math } \\
\text { assignments; written } \\
\text { application/analysis assignments; } \\
\text { group project work; individual written } \\
\text { term paper. }\end{array}$ & $\begin{array}{l}\text { Teaching presence includes course design and } \\
\text { organization, delivery, facilitating discourse, and } \\
\text { direct instruction; individualized feedback. } \\
\text { Student cognitive presence in class and on } \\
\text { performance assignments. } \\
\text { Faculty and student social presences exhibited. }\end{array}$ \\
\hline 5 pts. & $\begin{array}{l}\text { Application level and } \\
\text { above of taxonomy. } \\
\text { Extensive critical thinking } \\
\text { requires reasoning } \\
\text { through complexities and } \\
\text { ambiguities. }\end{array}$ & $\begin{array}{l}\text { Faculty instruction, extensive } \\
\text { substantive class discussion; } \\
\text { individual projects and papers, one } \\
\text { major; in-depth research on course } \\
\text { topic of interest. }\end{array}$ & $\begin{array}{l}\text { Teaching presence includes course design and } \\
\text { organization, delivery, facilitating discourse, and } \\
\text { direct instruction; individualized student } \\
\text { feedback. } \\
\text { Extensive student cognitive presence. } \\
\text { Well-developed faculty and student social } \\
\text { presences. }\end{array}$ \\
\hline
\end{tabular}

1. Indicate score for each column: Column A_C Column B_C Column $\mathrm{C}$ Note: when scores fall between 2 rows, circle both and assign a point score between the two rows.

2. Sum the scores from the 3 columns: Column $\mathrm{A}+$ Column $\mathrm{B}+$ Column $\mathrm{C}=$ Total course score of: . (Score range $=3-15)$.

3. Total score will identify the numerical parameters of class size. In the range of course sums below, circle the appropriate size for the course. 
One Size Does Not Fit All: Toward an Evidence-Based Framework

for Determining Online Course Enrollment Sizes in Higher Education

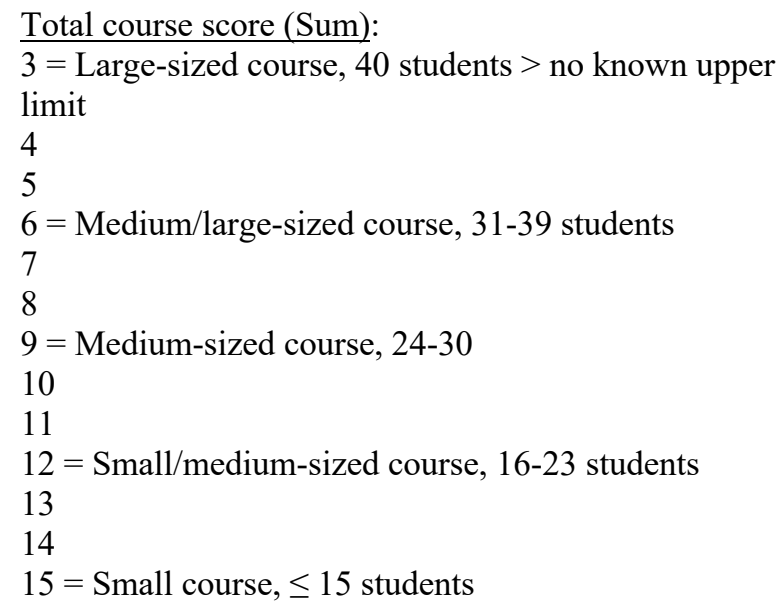

Evidence-based Class Size Guidelines:

Online Class Size

Small courses:

Small/medium courses: $\quad 16-23$

Medium courses: $\quad 24-30$

Medium/large courses: $\quad 31-39$

Large courses:

limit

This framework is an explicitly synthetic effort to present our understanding of the recent research literature, but it also aligns comfortably with our personal experiences as online educators. It is meant to be considered, discussed, challenged, and customized to particular settings. We offer it to introduce a process of inquiry and experimentation into decision-making about online class sizes that is worthy of the high educational stakes.

\section{Limitations}

This research was rooted in a systematic review of recent research articles published by education scholars from more than 43 cross-disciplinary education journals. Undoubtedly, there are relevant studies from outside of our search parameters residing in other publications or within educational settings. We welcome additional research insights to add to the compilation of evidence.

As learning technologies continue to advance, the potential exists for emerging discoveries to alter our understanding of learning processes, change pedagogical methods, and expand options for effective individualized online student learning. Over time these influences may transform the structure of learning systems and impact the factor of class size.

\section{Acknowledgment}

The authors gratefully acknowledge the significant role of the American Association of Colleges of Nursing (AACN) in repeatedly encouraging and showcasing the development of this research over a 5-year time frame and disseminating its results.

This research did not receive any specific grant from funding agencies in the public, commercial, or not-for-profit sectors. 
One Size Does Not Fit All: Toward an Evidence-Based Framework

for Determining Online Course Enrollment Sizes in Higher Education

\section{References}

Anderson, T., Rourke, L., Garrison, D. R., \& Archer, W. (2001). Assessing teaching presence in a computer conferencing context. Journal of Asynchronous Learning Networks, 5(2), 1-17. Retrieved from http://www.sloan-c.org/publications/jalnv5n2/pdf/v5n2 anderson.pdf

Arbaugh, J. R. (2007). An empirical verification of the community of inquiry framework. Journal of Asynchronous Learning Networks, 11(1). Retrieved from http://www.sloanc.org/publications/jaln/v111n1/v11n1_9arbaugh.as

Arbaugh, J. B., \& Benbunan-Fich, R. (2005). Contextual factors that influence ALN effectiveness. In S. R. Hiltz \& R. Goldman (Eds.), Learning together online: Research on asynchronous learning networks (pp. 123-44). Mahwah, NJ: Lawrence Erlbaum Associates, Publishers.

Arbaugh, J. B., \& Benbunan-Fich, R. (2006). An investigation of epistemological and social dimensions of teaching in online learning environments. Academy of Management Learning \& Education, 5(4), 435-447.

Arbaugh, J. B., Cleveland-Innes, M., Diaz, S. R., Garrison, D. R., Ice, P., Richardson, J. C., \& Swan, K. P. (2008). Developing a community of inquiry instrument: Testing a measure of the community of inquiry framework using a multi-institutional sample. Internet and Higher Education, 11(3), 133-136. doi:10.1016/j.iheduc.2008.06.003

Arias, J. J., \& Walker, D. M. (2004). Additional evidence on the relationship between class size and student performance. The Journal of Economic Education, 35(4), 311-329.

Armstrong, P. (n.d.). Bloom's taxonomy. Center for Teaching, Vanderbilt University. Retrieved from https://cft.vanderbilt.edu/guides-sub-pages/blooms-taxonomy/

Artemiou, E., Adams, C. L., Vallevand, A., Violato, C., \& Hecker, K. G. (2013). Measuring the effectiveness of small-group and web-based training methods in teaching clinical communication: A case comparison study. Journal of Veterinary Medical Education, 40(3), 242-51. doi:10.3138/jvme.0113-026R1

Arzt, J. (2011, October 21). Online courses and optimal class size: A complex formula. Unpublished manuscript, St. Joseph College. Retrieved from http://files.eric.ed.gov/fulltext/ED529663.pdf

Bain, K. (2004). What the best college teachers do. Cambridge, MA: Harvard University Press.

Batts, D. (2008, December). Comparison of student and instructor perceptions of best practices in online technology courses. Merlot Journal of Online Teaching and Learning, 4(4), 477-489. Retrieved from http://jolt.merlot.org/vol4no4/batts 1208.pdf

Beattie, I. R., \& Thiele, M. (2016). Connecting in class? College class size and inequality in academic social capital. The Journal of Higher Education, 87(3), 332-362.

Bedard, K., \& Kuhn, P. (2008). Where class size really matters: Class size and student ratings of instructor effectiveness. Economics of Education Review, 27(3), 253-265.

Benbunan-Fich, R., Hiltz, S. R., \& Harasim, L. (2005). The online interaction learning model: An integrated theoretical framework for learning networks. In S. R. Hiltz \& R. Goldman (Eds.), Learning together online: Research on asynchronous learning networks (pp. 19-37). Mahwah, NJ: Erlbaum.

Benton, S. L., \& Pallett, W. H. (2013, January). Class size matters. Inside Higher Education. Retrieved from https://www.insidehighered.com/views/2013/01/29/essay-importance-class-size-highereducation.

Berg, M., \& Seeber, B. K. (2016). The slow professor: Challenging the culture of speed in the academy. Toronto: University of Toronto Press. 
One Size Does Not Fit All: Toward an Evidence-Based Framework

for Determining Online Course Enrollment Sizes in Higher Education

Bettinger, E., Doss, C., Loeb, S., Rogers, E., \& Taylor, E. (2017, June). The effects of class size in online college courses: Experimental evidence. Economics of Education Review, 58, 68-95. doi:10.1016/J.ECONEDUREV.2017.03.006

Bettinger, E., \& Loeb, S. (2017). Promises and pitfalls of online education. Brookings. Retrieved from https://www.brookings.edu/research/promises-and-pitfalls-of-online-education/

Betts, K. (2008). Online Human Touch (OHT) instruction and programming: A conceptual framework to increase student engagement and retention in online education, Part 1. MERLOT Journal of Online Learning and Teaching, 4(3), 399-418.

Blatchford, P., Bassett, P., \& Brown, P. (2011). Examining the effect of class size on classroom engagement and teacher-pupil interaction: Differences in relation to pupil prior attainment and primary vs. secondary schools. Learning and Instruction, 21(6), 715-730. doi:10.1016/j.learninstruc.2011.04.001

Bloom, B. (Ed.), Englehart, M. D., Furst, E. J., Hill, W. H., \& Krathwohl, D. R. (1956). Taxonomy of educational objectives: The classification of educational goals. Handbook I: Cognitive domain. New York: David McKay Co., Inc.

Bozkurt, A., Akgun-Ozbek, E., Yilmazel, S., Erdogdu, E., Ucar, H., Guler, E., ... Aydin, C. H. (2015). Trends in distance education research: A content analysis of journals 2009-2013. International Review of Research in Open and Distributed Learning, 16(1), 330-363. Retrieved from http://www.irrodl.org/index.php/irrodl/article/view/1953/3192

Bristol, T. J., \& Kyarsgaard, V. (2012). Asynchronous discussion: A comparison of larger and smaller discussion group size. Nursing Education Perspectives, 33(6), 386-390.

Brook, C., \& Oliver, R. (2003). Online learning communities: Investigating a design framework. Australian Journal of Educational Technology, 19(2), 139-60.

Chapman, L., \& Ludlow, L. (2010). Can downsizing college class sizes augment student outcomes? An investigation of the effects of class size on student learning. The Journal of General Education, 59(2), 105-123. doi:10.5325/jgeneeduc.59.2.0105

Chen, B., deNoyelles, A., Zydney, J., \& Patton, K. (2017). Creating a community of inquiry in largeenrollment online courses: An exploratory study on the effect of protocols within online discussions. Online Learning, 21(1), 165-188. doi:10.24059/olj.v21i1.816

Cheng, D.A. (2011). Effects of class size on alternative educational outcomes across disciplines. Economics of Education Review, 30(5), 980-990.

Chu, S. K. W., Zhang, Y., Chen, K., Chan, C. K., Lee, C. W. Y., Zou, E., \& Lau, W. (2017). The effectiveness of wikis for project-based learning in different disciplines in higher education. Internet and Higher Education, 33, 49-60. doi:10.1016/j.iheduc.2017.01.005

Colwell, J., \& Jenks, C. (2004). The upper limit: The issues for faculty in setting class size in online courses. Proceedings from Conference, Teaching Online in Higher Education 2004 (TOHE). Retrieved from https:/www.utm.edu/departments/ncate/documents/015 theupperlimit.pdf

Curriculum Committee. The Academic Senate for California Community Colleges. (2012). Setting course enrollment maximums: Process, roles, and principles. Retrieved from http://www.asccc.org/sites/default/files/ClassCapsS12 0.pdf

Diette, T. M., \& Raghav, M. (2015). Class size matters: Heterogeneous effects of larger classes on college student learning. Eastern Economic Journal, 41(2), 273-283.

De Giorgi, G., Pellizzari, M., \& Woolston, W. G. (2012). Class size and class heterogeneity. Journal of the European Economic Association, 10(4), 795-830. doi:10.1111/j.1542-4774.2012.01073.x 
One Size Does Not Fit All: Toward an Evidence-Based Framework

for Determining Online Course Enrollment Sizes in Higher Education

El Tantawi, M. M. A., Abdelsalem, M. M., Mourady, A. M., \& Elrifae, I. M. B. (2015). e-Assessment in a limited-resources dental school using an open-source learning management system. Journal of Dental Education, 79(5), 571-583. Retrieved from http://www.jdentaled.org/content/79/5/463.full

Fischer, G. (2014). Commentary: Beyond hype and underestimation: Identifying research challenges for the future of MOOCs. Distance Education, 35(2), 149-158. doi:10.1080/01587919.2014.920752

Freeman, L. A. (2015). Instructor time requirements to develop and teach online courses. Online Journal of Distance Learning Administration, 18(1). Retrieved from http://www.westga.edu/ distance/ojdla/spring181/freeman181.html

Garrison, D. R. (2007). Online community of inquiry review: Social, cognitive, and teaching presence issues. Journal of Asynchronous Learning Networks, 11(1). Retrieved from http://www.sloanc.org/publications/JALN/v11n1/v11n1_8garrison.asp

Garrison, D. R. (2012). Article review - Social presence within the community of inquiry framework. International Review of Research in Open and Distributed Learning, 13(1). Retrieved from http://www.irrodl.org/index.php/irrodl/article/view/1184/2099

Garrison, D. R., Anderson, T., \& Archer, W. (2000). Critical inquiry in a text-based environment: Computer conferencing in higher education. Internet and Higher Education, 2(3), 87-105.

Garrison, D.R., Anderson, T., \& Archer, W. (2010). The first decade of the community of inquiry framework: A retrospective. Internet and Higher Education, 13(1-2), 5-9.

Garrison, D. R., Cleveland-Innes, M., \& Fung, T. S. (2010). Exploring causal relationships among teaching, cognitive and social presence: Student perceptions of the community of inquiry framework. Internet and Higher Education, 13(1-2), 31-36.

Gleason, J. (2012). Using technology-assisted instruction and assessment to reduce the effect of class size on student outcomes in undergraduate mathematics courses. College Teaching, 60(3), 87-94.

Goldman, Z. (2012). Online MBA asynchronous discussion workload and value perceptions for instructors and learners: Working toward an integrated educational model for professional adults. Journal of Online Learning and Teaching, 8(3). Retrieved from http://jolt.merlot.org/vol8no3/goldman 0912.htm

Haynie, D. (2014, September 26). Experts say class size can matter for online students. U.S. News \& World Report, Higher Education. Retrieved from http://www.usnews.com/education/onlineeducation/articles/2014/09/26/experts-say-class-size-can-matter-for-online-students

Hew, K. F., \& Cheung, W. S. (2011). Higher-level knowledge construction in asynchronous online discussions: An analysis of group size, duration of online discussion, and student facilitation techniques. Instructional Science, 39(3), 303-319. Retrieved from http://www.jstor.org/stable/23882804

Hewitt, J., \& Brett, C. (2007). The relationship between class size and online activity patterns in asynchronous computer conferencing environments. Computers \& Education, 49(4), 1258-1271. doi:10.1016/j.compedu.2006.02.001

Holtslander, L. F., Racine, L., Furniss, S., Burles, M., \& Turner, H. (2012). Developing and piloting an online graduate nursing course focused on experiential learning of qualitative research methods. Journal of Nursing Education, 51(6), 345-348.

Holzweiss, P. C., Joyner, S. A., Fuller, M. B., Henderson, S., \& Young, R. (2014). Online graduate students' perceptions of best learning experiences. Distance Education, 35(3), 311-323. doi:10.1080/01587919.2015.955262

Horning, A. (2007, Fall/Winter). The definitive article on class size. WPA, Writing Program Administration, 31(1-2), 11-34. Councils of Writing Program Administrators. Retrieved from http://wpacouncil.org/archives/31n1-2/31n1-2horning.pdf 
One Size Does Not Fit All: Toward an Evidence-Based Framework

for Determining Online Course Enrollment Sizes in Higher Education

Jaggars, S. S., \& Xu, D. (2016). How do online course design features influence student performance? Computers \& Education, 95, 270-284. doi:10.1016/J.COMPEDU.2016.01.014

Jahang, N., Nielsen, W., \& Chan, E. (2010). Collaborative learning in an online course: A comparison of communication patterns in small and whole group activities. Journal of Distance Education, 24(2), 39-58.

Joksimović, S., Gašević, D., Kovanović, V., Riecke, B. E., \& Hatala, M. (2015). Social presence in online discussions as a process predictor of academic performance. Journal of Computer Assisted Learning, 31(6), 638-654. doi:10.1111/jcal.12107

Johnson, I. (2010). Class size and student performance at a public research university: A cross-classified model. Research in Higher Education, 51(8), 701-723.

Jones, S. H. (2015). Benefits and challenges of online education for clinical social work: Three examples. Clinical Social Work Journal, 43(2), 225-235.

Kasi, E., \& Yorks, L. (2016). Do I really know you? Do you really know me? Empathy amid diversity in differing learning contexts. Adult Education Quarterly, 66(1), 3-20. doi: $10.1177 / 0741713615606965$

Kim, J. (2013, March). Influence of group size on students' participation in online discussion forums. Computers \& Education, 62, 123-129. doi:10.1016/j.compedu.2012.10.025

Kingma, B., \& Keefe, S. (2006). An analysis of the virtual classroom: Does size matter? Do residencies make a difference? Should you hire that instructional designer? Journal of Education for Library and Information Science, 47(2), 127-143.

Lahaie, U. (2007). Strategies for creating social presence online. Nurse Educator, 32(3), 100-101.

Lai, K. (2015). Knowledge construction in online learning communities: A case study of a doctoral course. Studies in Higher Education, 40(4), 561-579.

Lee, S., Dapremont, J., \& Sasser, J. (2011). Nursing students' perception of class size and its impact on test performance: A pilot study. Journal of Nursing Education, 50(12), 715-718.

Legg, T. J., Adelman, D., \& Levitt, C. (2009). Constructivist strategies in online distance education in nursing. Journal of Nursing Education, 48(2), 64-69.

Leppa, C. J. (2004). Assessing student critical thinking through online discussions. Nurse Educator, 29(4), 156-60.

Lindley, M. K. Ashwill, R., Cipher, D. J., \& Mancini, M. E. (2017). Expanding capacity with an accelerated on-line BSN program. Journal of Professional Nursing, 33(1), 5-10.

Liu, O. L. (2012). Student evaluation of instruction: In the new paradigm of distance education. Research in Higher Education, 53(4), 471-486. doi:10.1007/s11162-011-9236-1

Mandel, P., \& Sussmuth, B. (2011). Size matters. The relevance and Hicksian surplus of preferred college class size. Economics of Education Review, 30(5), 1073-1084.

Mandernach, B. J., \& Holbeck, R. (2016). Teaching online: Where do faculty spend their time? Online Journal of Distance Learning Administration, 19(4). Retrieved from http://www.westga.edu/\%7Edistance/ojdla/winter194/mandernach_holbeck194.html

Maringe, F., \& Sing, N. (2014, June). Teaching large classes in an increasingly internationalising higher education environment: Pedagogical, quality and equity issues. Higher Education: The International Journal of Higher Education and Educational Planning, 67(6), 761-782.

Mbati, L., \& Minnaar, A. (2015, April). Guidelines towards the facilitation of interactive online learning programmes in higher education. International Review of Research in Open and Distributed Learning, 16(2). Retrieved from http://www.irrodl.org/index.php/irrodl/article/view/2019/3269 
One Size Does Not Fit All: Toward an Evidence-Based Framework

for Determining Online Course Enrollment Sizes in Higher Education

Means, B., Toyama, Y., Murphy, R., Bakia, M., \& Jones, K.; Office of Planning, Evaluation, and Policy Development, Policy and Program Studies Service: U.S. Department of Education. (2010).

Evaluation of evidence based practices in online learning: A meta-analysis and review of online learning studies. Retrieved from https://www2.ed.gov/rschstat/eval/tech/evidence-basedpractices/finalreport.pdf

Meyer, K. A. (2006). The method (and madness) of evaluating online discussions. Journal of Asynchronous Learning Networks, 10(4), 83-97.

Monks, J., \& Schmidt, R. M. (2011). The impact of class size on outcomes in higher education. The BE Journal of Economic Analysis and Policy, 11(1), 1-17.

Morrison, D. (2015, January). Does class size matter in online courses? Three perspectives: The economist, instructor \& student. Online Learning Insights. Retrieved from https://onlinelearninginsights.wordpress.com/2015/01/14/does-class-size-matter-in-onlinecourses-three-perspectives/

Morse, R., Brooks, E., \& Mason, M. (2018). How U.S. News calculated the 2019 best colleges rankings. Retrieved from https://www.usnews.com/education/best-colleges/articles/how-us-news-calculated-the-rankings

Mupinga, D. M., \& Maughan, G. R. (2008). Web-based instruction and community college faculty workload. College Teaching, 56(1), 17-21.

Orcutt, J. M., \& Dringus, L. P. (2017). Beyond being there: Practices that establish presence, engage students and influence intellectual curiosity in a structured online learning environment. Online Learning, 21(3), 15-35. doi:10.24059/olj.v\%vi\%i.1231

Palmer, S., \& Smith, C. (2013). Updating RIGs: Including the systematic influence of online study on student evaluation of teaching. Educational Research and Evaluation, 19(1), 77-90.

Parks-Stamm, E. J., Zafonte, M., \& Palenque, S. M. (2016, September 29). The effects of instructor participation and class size on student participation in an online class discussion forum. British Journal of Educational Technology, 48(6), 1250-1259. doi:10.1111/bjet.12512

Paulus, T. M., Myers, C. R., Mixer, S. J., Wyatt, T. H., Lee, D. S., \& Lee, J. L. (2010). For faculty, by faculty: A case study of learning to teach online. International Journal of Nursing Education Scholarship, 7(1), 1-16. doi:10.2202/1548-923X.1979

Pelech, W., Wulff, D., Perrault, E., Ayala, J., Baynton, M., Williams, M., Crowder, R., \& Shankar, J. (2013). Current challenges in social work distance education: Responses from the Elluminati. Journal of Teaching in Social Work, 33(4-5), 393-407. doi:10.1080/08841233.2013.834863

Picciano, A. G. (2017). Theories and frameworks for online education: Seeking an integrated model. Online Learning, 21(3), 166-190. doi:10.24059/olj.v21i3.1225

Qiu, M., Hewitt, J., \& Brett, C. (2012, September). Online class size, note reading, note writing and collaborative discourse. International Journal of Computer-Supported Collaborative Learning, 7(3), 423-442. doi:10.1007/s11412-012-9151-2

Ravenna, G. (2012). The effects of increased workloads on online instruction. International Journal of Education, 4(4), 125-133. doi:10.5296/ije.v4i4.2269

Rees, J. (2017, May 22). You can't automate good teaching. ChronicleVitae, The Chronicle of Higher Education. Retrieved from https://chroniclevitae.com/news/1804-you-can-t-automategoodteaching? cid $=$ wb\&utm source $=$ wb\&utm medium $=\% 20$ en\&elqTrackId $=\mathrm{c} 38776 \mathrm{db} 41 \mathrm{be} 4214$ $\underline{8 \mathrm{fc} 8265 \mathrm{~cd} 2 \mathrm{bc} 08 \mathrm{~b} 6 \& \mathrm{elq}=75265 \mathrm{e} 863 \mathrm{~d} 3 \mathrm{a} 40 \mathrm{~b} 6989 \mathrm{~d} 358 \mathrm{bb} 0911 \mathrm{f} 34 \& \text { elqaid=14105\&elqat }=1 \& \mathrm{elqCa}}$ mpaignId $=5909$ 
One Size Does Not Fit All: Toward an Evidence-Based Framework

for Determining Online Course Enrollment Sizes in Higher Education

Richardson, J. C., Koehler, A. A., Besser, E. D., Caskurlu, S., Lim, J., \& Mueller, C. M. (2015, June). Conceptualizing and investigating instructor presence in online learning environments. International Review of Research in Open and Distributed Learning, 16(3). Retrieved from http:/www.irrodl.org/index.php/irrodl/article/view/2123/3349

Roby, T., Ashe, S., Singh, N., \& Clark, C. (2013, April). Shaping the online experience: How administrators can influence student and instructor perceptions through policy and practice. Internet and Higher Education, 17, 29-37. doi:10.1016/j.iheduc.2012.09.004

Russell, B. H. (2015). The who, what, and how of evaluation within online nursing education: State of the science. Journal of Nursing Education, 54(1), 13-21.

Russell, V., \& Curtis, W. (2013, January). Comparing a large- and small-scale online language course: An examination of teacher and learner perceptions. Internet and Higher Education, 16, 1-13. doi:10.1016/j.iheduc.2012.07.002

Salley, W., \& Shaw, M. (2015). Employment status, teaching load, and student performance in online community college courses. Online Journal of Distance Learning Administration, 18(2).

Retrieved from http://www.westga.edu/ distance/ojdla

Sapelli, C., \& Illanes, G. (2016, June). Class size and teacher effects in higher education. Economics of Education Review, 52, 19-28. doi:10.1016/j.econedurev.2016.01.001

Schellens, T., \& Valcke, M. (2006). Fostering knowledge construction in university students through asynchronous discussion groups. Computers \& Education, 46(4), 349-370.

Seethamraju, R. (2014). Effectiveness of using online discussion forum for case study analysis. Education Research International, 2014. doi:10.1155/2014/589860

Schwartz, M. (2014). KHAN Academy: The illusion of understanding. Journal of Asynchronous Learning Networks, 17(4), 67-79.

Seaton, J. X., \& Schwier, R. (2014). An exploratory case study of online instructors: Factors associated with instructor engagement. International Journal of E-Learning \& Distance Education, 29(1), 1-16. Retrieved from http://ijede.ca/index.php/jde/article/view/870/1536

Shaw, R-S. (2013, March). The relationships among group size, participation, and performance of programming language learning supported with online forums. Computers \& Education, 62, 196 207. doi:10.1016/j.compedu.2012.11.001

Shea, P. (2006). A study of students' sense of learning community in online environments. Journal of Asynchronous Learning Networks, 10(1), 35-44.

Smith, G. S., Brashen, H. M., Minor, M. A, \& Anthony, P. J. (2015). Stress: The insidious leveler of good, unsuspecting, online instructors of higher education. Journal of Social Change, 7(1), 5668. doi:10.5590/JOSC.2015.07.1.05

Snowball, J.D. (2014). Using interactive content and online activities to accommodate diversity in a large first year class. Higher Education, 67(6), 823-838. Retrieved from https://doi.org/10.1007/s10734-013-9708-7

Sorensen, C. (2014, December). Classrooms without walls: A comparison of instructor performance in online courses differing in class size. MERLOT Journal of Online Learning and Teaching, 10(4), $569-576$.

Sorensen, C. (2015). An examination of the relationship between online class size and instructor performance. Journal of Educators Online, 12(1), 140-159. Retrieved from https://www.thejeo.com/archive/2015_12_1/Sorensen

Stein, D. S., Wanstreet, C. E., Slagle, P., Trinko, L. A., \& Lutz, M. (2014). From 'hello' to higher-order thinking: The effect of coaching and feedback on online chats. Internet and Higher Education, 16, 78-84. doi:10.1016/j.iheduc.2012.03.001 
One Size Does Not Fit All: Toward an Evidence-Based Framework

for Determining Online Course Enrollment Sizes in Higher Education

Swan, K., \& Ice, P. (2010). Preface: The community of inquiry framework ten years later: Introduction to the special issue. Internet and Higher Education, 13(1-2), 1-4. doi:10.1016/j.iheduc.2009.11.003

Swan, K., \& Shea, P. (2005). The development of virtual learning communities. In S. R. Hiltz \& R. Goldman (Eds.), Learning together online: Research on asynchronous learning networks (pp. 239-60). Mahwah, NJ: Lawrence Erlbaum Associates, Publishers.

Sword, T. S. (2012). The transition to online teaching as experienced by nurse educators. Nursing Education Perspectives, 33(4), 269-271.

Taft, S. H., Perkowski, T., \& Martin, L. S. (2011). A framework for evaluating class size in online education. Quarterly Review of Distance Education, 12(3), 181-97.

Tomei, L. A. (2006). The impact of online teaching on faculty load: Computing the ideal class size for online courses. Journal of Technology and Teacher Education, 14(3), 531-541.

Tynan, B., Ryan, Y., \& Lamont-Mills, A. (2015, January). Examining workload models in online and blended teaching. British Journal of Educational Technology, 46(1), 5-15.

Udermann, B. (2015). Does Class Size Matter? Distance Education Report, 19(10), 3-7.

Walls, J. K. (2016). A theoretically grounded framework for integrating the scholarship of teaching and learning. Journal of the Scholarship of Teaching and Learning, 16(2), 39-49. doi:10.14434/josotl.v16i2.19217

Watson, K., Handal, B., \& Maher, M. (2016). The influence of class size upon numeracy and literacy performance. Quality Assurance in Education, 24(4), 507-527.

Williams, S. S., Jaramillo, A., \& Pesko, J. C. (2015). Improving depth of thinking in online discussion boards. Quarterly Review of Distance Education, 16(3), 45-66.

$\mathrm{Xu}, \mathrm{D}$., \& Jaggars, S. S. (2014). Performance gaps between online and face-to-face courses: Differences across types of students and academic subject areas. The Journal of Higher Education, 85(5), 633-659. 